\title{
PALEOLIQUEFACTION STUDIES IN CONTINENTAL SETTINGS: GEOLOGIC AND GEOTECHNICAL FACTORS IN INTERPRETATIONS AND BACK-ANALYSIS
}

\author{
By Stephen F. Obermeier ${ }^{1}$, Eric C. Pond ${ }^{2}$, and Scott M. Olson ${ }^{3}$ \\ With contributions by Russell A. Green ${ }^{4}$, Timothy D. Stark ${ }^{5}$, and James K. Mitchell ${ }^{6}$
}

${ }^{1}$ Emeritus, U.S. Geological Survey, Reston, Virginia; EqLiq Consulting; sobermei@yahoo.com

${ }^{2}$ Kleinfelder Inc., Consulting Engineers, Alberquerque, New Mexico; epond@kleinfelder.com

${ }^{3}$ Dept. of Civil and Environmental Engineering, Univ. of Illinois, Urbana, Illinois; scott_olson@urscorp.com

${ }^{4}$ Dept. of Civil and Environmental Engineering, Virginia Tech, Blacksburg, Virginia

${ }^{5}$ Prof., Dept. of Civil and Environmental Engineering, Univ. of Illinois, Urbana, Illinois

${ }^{6}$ Distinguished Prof., Dept. of Civil and Environmental Engineering, Virginia T ech, Blacksburg, Virginia

US GEOLOGICAL SURVEY OPEN-FILE REPORT 01-29

2001 
PALEOLIQUEFACTION STUDIES IN CONTINENTAL SETTINGS:

GEOLOGIC AND GEOTECHNICAL FACTORS IN

INTERPRETATIONS AND BACK-ANALYSIS

\section{INTRODUCTION}

THE PROCESS OF LIQUEFACTION AND ITS MANIFESTATIONS

The Basic Process

Liquefaction Susceptibility

Field Conditions Favorable for Formation of Liquefaction Features

Mechanisms that Form Liquefaction Features

The various ground-failure mechanisms.

Factors controlling the mechanisms of ground failure.

Field examples of various manifestations of liquefaction.

WHERE WAS THE SOURCE REGION?

DID SHAKING OCCUR WITHOUT LEAVING LIQUEFACTION EVIDENCE?

Effects of Strength of Shaking and Liquefaction Susceptibility

Effect of Grain Size

Effect of Depth to Water Table

HOW STRONG WAS THE PALEO-EARTHQUAKE?

Magnitude Bound Method

Case history examples and field verification.

Water table depth.

Cyclic Stress Method

Application to paleoliquefaction studies.

Case history examples.

Energy-Based Approaches

Field case histories using Gutenberg-Richter relations.

Laboratory test results.

Arias Intensity method.

Ishihara Method

SUMMARY AND CONCLUDING COMMENTARY

ACKNOWLEDGMENTS

REFERENCES CITED

APPENDIX: DEFINITIONS OF TERMS 


\title{
PALEOLIQUEFACTION S TUDIES IN CONTINENTAL SETTINGS : GEOLOGIC AND GEOTECHNICAL FACTORS IN INTERPRETATIONS AND BACK-ANALYSIS
}

\author{
By Stephen F. Obermeier, Eric C. Pond, and Scott M. Olson \\ With contributions by Russell A. Green, Timothy D. Stark, and James K. Mitchell
}

\begin{abstract}
Paleoliquefaction research in the last 15 years has greatly improved our ability to interpret the paleoseismic record throughout some large geographic areas, especially in regions of infrequent large earthquakes. Paleoliquefaction studies have been used extensively in the central and eastern U.S. to assess seismic hazards, and could be used elsewhere to good purpose because paleoliquefaction studies in some field settings can reveal more than other methods, such as fault studies, about the prehistoric strength of shaking and earthquake magnitude.
\end{abstract}

We present guidelines for the conduct of a paleoliquefaction study in continental deposits, mainly in terms of the geologic/seismologic setting and geotechnical properties, because a successful interpretation requires factors from all these disciplines. No single discipline suffices alone. Their interactions must be appreciated in order to understand why seismically induced liquefaction features are found in some locales and not in others.

The guidelines that we present also relate to three primary issues for which liquefaction features are especially useful for interpretations: Where was the tectonic source? What was the strength of shaking? And what was the magnitude? In discussing these issues we focus on the following aspects of level-ground liquefaction: (1) mechanisms that form seismic liquefaction features in the field; (2) field settings where liquefaction features should be present if strong seismic shaking has occurred; (3) field settings where an absence of liquefaction features indicates an absence of strong seismic shaking; (4) how liquefaction features should be used to interpret the tectonic source locale of a paleo-earthquake; and (5) how effects of liquefaction can be used to back-calculate the strength of shaking as well as earthquake magnitude.

Several methods are available to back-calculate the strength of shaking and earthquake magnitude, and the most commonly used methods are presented and critiqued. Our critique of these methods points out the uncertainties attending each. Paleoliquefaction/paleoseismic case histories are presented to illustrate potential uncertainties in back-calculations and procedures to overcome these uncertainties.

Reasonable confidence in paleoseismic interpretation generally requires using multiple methods of backanalysis, and achieving similar results from each method. An alternate approach can be used for paleoearthquakes that were large enough to have caused liquefaction in a variety of geologic settings, in which there were differing factors affecting surface ground motions and liquefaction susceptibility. For this situation, a method such as the cyclic-stress method can be used to make back-calculations that can be crosschecked with results from other settings. 


\section{INTRO DUCTION}

The study of paleoliquefaction features for seismic analysis is a new and increasingly utilized technique. Developed only over the past 15 years, the method of systematically searching for paleoliquefaction features throughout large geographic areas is being used to interpret the paleoseismic record through much of the Holocene and into latest Pleistocene time. Widespread locales have been searched, chiefly in the southeastern, central, and northwestern U.S., where physical settings and seismotectonic conditions differ greatly from one another. Despite extensive reliance on paleoliquefaction studies in the central and eastern parts of the U.S., the scope of their capabilities is not widely appreciated even within the community of paleoseismic researchers. For example, it is not well known that geologic field observations alone can yield important clues about the severity of earthquake shaking and, in many settings, the probable location of the tectonic source zone. Nor is it well known that procedures utilizing geotechnical and seismological data can rely on paleoliquefaction effects in many settings to make estimates of prehistoric accelerations and magnitudes. Realistic estimates can be made in many field settings using these procedures, even though some of the procedures are very recent and not fully developed and no one procedure is applicable in all situations.

Despite the recent development of paleoliquefaction studies, the techniques that are used in continental settings (such as the geographic continental U.S.) to search for paleoliquefaction features and to verify a seismic origin for suspected features are well developed (Obermeier, 1996a). In contrast, some uncertainty is often inherent in using a single procedure to backcalculate the strengths of shaking and magnitude (Olson et al., 2001). For some situations this uncertainty can be large, making it desirable to use more than one method as a means for crosschecking. Most of these procedures for back-calculation are evolving rapidly.

This paper summarizes and critiques issues concerning field searches for paleoliquefaction features as well as the interpretation and back-analysis of strength of shaking and earthquake magnitude using geologic and geotechnical-seismological procedures. The paper is restricted to liquefaction features that developed on ground that was level or nearly so (less than a few degrees in slope) when an earthquake struck, thereby excluding effects such as slumps and flow failures (i.e., debris flows induced by liquefaction), which may occur on steeper slopes. Such failures on steeper slopes are very difficult to back-analyze for strength of shaking and earthquake magnitude, and thus their usefulness is limited, in contrast to level-ground liquefaction-induced failures. This paper focuses on the following aspects of level-ground liquefaction: (1) mechanisms that form seismic liquefaction features in the field; (2) field settings where liquefaction features should be present if strong seismic shaking has occurred; (3) field settings where an absence of paleoliquefaction features indicates an absence of strong paleoseismic shaking; (4) how liquefaction features should be used to interpret the tectonic source region of a paleo-earthquake; and (5) how effects of liquefaction can be used to interpret the strength of prehistoric shaking as well as the paleomagnitude. The wide scope of the paper includes material relevant to geologists, seismologists, and engineers. Some of the material in this paper is intended for the initiate who is 
interested in practical aspects of conducting a paleoliquefaction study, because no such guidelines are available elsewhere. But much of the paper is relevant to the specialist, particularly the sections concerned with back-analysis of the strength of previous shaking.

Before addressing these topics, though, a brief discussion of the process of liquefaction is useful, especially as the process relates to the manifestations of liquefaction in most field settings. This short summary is restricted to features that characteristically form in a clay- or silt-rich layer (i.e., host) lying above a liquefied sand-rich deposit. Our discussion is based on the premise that collecting adequate data for the analyses described herein requires searching over a large area, at least tens of kilometers in radius, and over a much larger region in most locales. Many kilometers of exposures must be examined, often at scattered places. In most field situations the only practical means of doing this is by searching banks of ditches or streams.

The paleoliquefaction record extends through much of Holocene time and into the latest Pleistocene at many places. A typical setting for paleoliquefaction features of these ages is in a valley of a moderate to a large river, on the modern flood plain or on a terrace that is only a few meters higher, where the depth to the water table is less than several meters and where there are thick sandy deposits. The liquefaction-induced features most commonly found here are steeply dipping, tabular, clastic fillings (dikes) that cut a fine-grained host. The typical morphology of such dikes in sectional view is illustrated in Figure 1. Features that are much more irregular than those shown in Figure 1 commonly abound where liquefaction has been especially severe. Intrusions more horizontally inclined, such as the sills depicted in Figure 2, also abound in many field settings.

The discussion will not include deformations of soft sediments that involve plastic deformation of muds and freshly deposited cohesionless sediments, such as load casts, ball-and-pillows, convoluted bedding, etc. (Allen, 1982; Obermeier, 1996a). Such features are not within the class of "liquefaction-induced features" that we consider in this paper because of the secondary role of elevated pore-water pressure that typically is involved in their formation. Furthermore, not only is a seismic origin often difficult to verify for plastically deformed soft sediments, but they commonly form without seismic shaking at such low levels as not to be relevant to seismic hazards (e.g, Sims, 1975).

Conversely, the origin of clastic dikes can usually be determined rather easily. And, seismically induced liquefaction features such as as dikes and sills typically involve a very significantly elevated pore-water pressure. Their formation typically requires a significant strength or duration of strong shaking, and thus they are more relevant to the assessment of seismic hazards. The minimum earthquake magnitude to form liquefaction features in most field settings is about moment magnitude M 5.5 (Ambraseys, 1988), which is about the same as the threshold for damage to man-made structures. (In this article the earthquake magnitude $(\mathbf{M})$ is always moment magnitude.) The minimum value of peak accelerations required for formation of liquefaction features decreases with increasing magnitude, with reported values as low as $0.025 \mathrm{~g}$ for $\mathbf{M} 8.25$ and $0.12 \mathrm{~g}$ for M 5.5 (Carter and Seed, 1988). It is commonly accepted that the vibration frequencies of interest are less than about ten $\mathrm{Hz}$, because higher frequencies do not induce shear strains large enough to break down the grain-to-grain contacts in granular sediments unless accelerations are extremely large. 


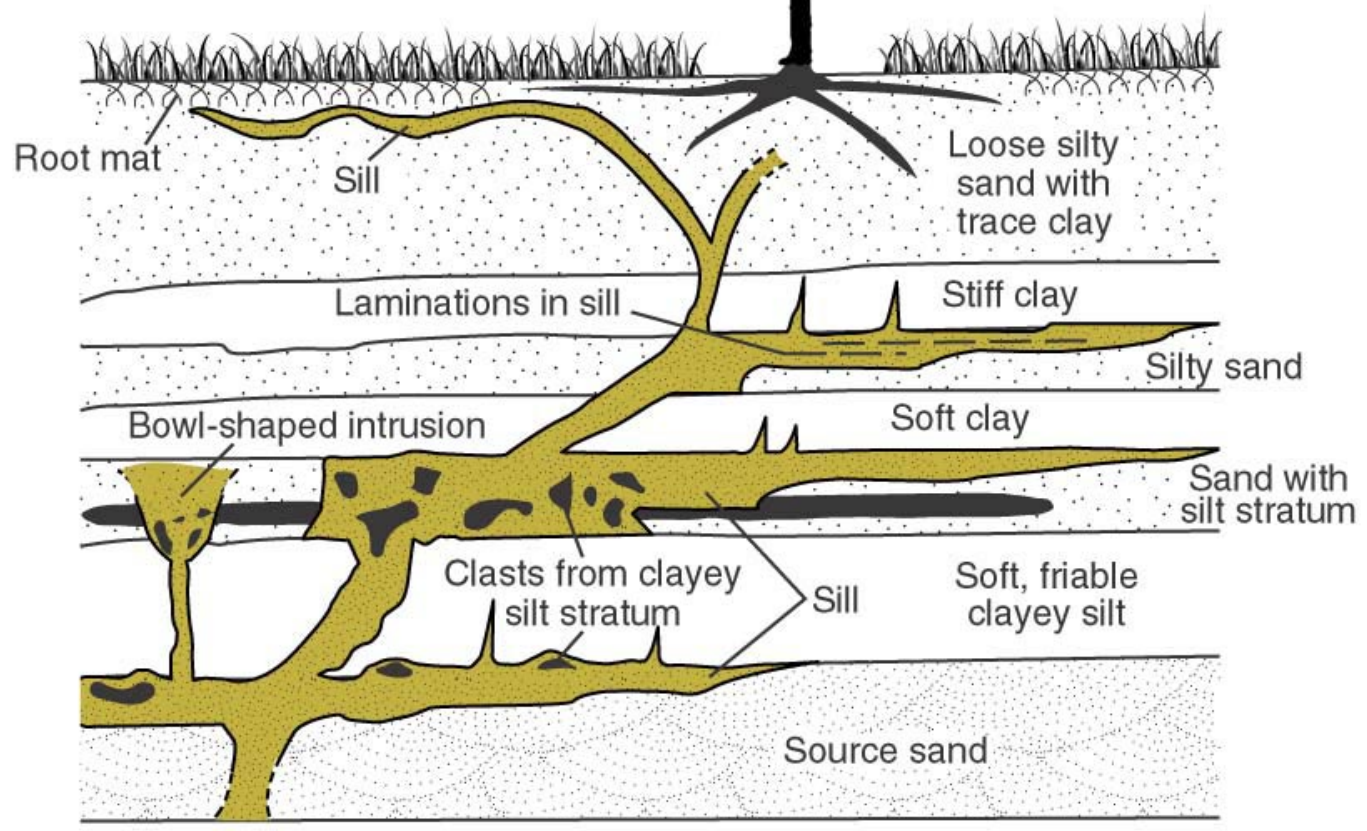

Figure 2. Schematic vertical section showing where sills form preferentially. Length of sketch represents $10-100 \mathrm{~m}$. Height represents $3-5 \mathrm{~m}$. Such severe sill development is typically accompanied by venting of sand to the surface. (From Obermeier, 1996a) 
In this paper we do not attempt a comprehensive technical discussion of many issues, nor do we give more than a limited list of references. Rather, we generally direct the reader to articles that contain expanded discussions and comprehensive references. The following section concerning the process of liquefaction and its manifestations is basically excerpted from articles by Obermeier (1996a, 1998b), which are largely compendia that focus on the formation of liquefaction-induced features and their use for paleoseismic interpretations. The interested reader is referred to excellent articles by Seed (1979), Ishihara (1985), Castro (1987, 1995) and Dobry (1989) for overviews of the liquefaction process. Some recent critiques of the geotechnical and seismological assumptions implicit in the procedures most commonly used for back-calculations are presented by Trifunac (1995; 1999), Pond (1996), Obermeier (1998a), and Olson et al. (2001).

For a discussion of seismically induced liquefaction features that characteristically form in a field setting where sand is encountered at the ground surface, without a fine-grained cap, the reader is referred to Obermeier (1996a). Obermeier (1998b) presents numerous photographs showing the types of features observed in various types of field settings, with and without a fine-grained cap.

A fewterms whose definitions are not well defined in the scientific community, and which require a more detailed discussion, are noted with bold italics in the text. Our usage of these terms is in the Appendix.

\section{THE PROCESS OF LIQ UEFACTION AND ITS MANIFESTATIO NS}

\section{The Basic Process}

We define liquefaction as the transformation of a saturated granular material from a solid to a liquefied state as a consequence of increased pore-water pressure, following the usage of Seed and Idriss (1971) and Youd (1973). Liquefaction is caused primarily by the application of shear stresses and accumulation of shear strain, resulting in a breakdown of the soil skeleton and buildup of interstitial pore-water pressure. The process typically occurs in sediments that are cohesionless or nearly so, and most readily in fine- to coarse-grained sands, especially where uniformly sized. The liquefied mixture of sand and water acts as a viscous liquid with a greatly reduced shear strength. Whereas this paper deals almost exclusively with liquefaction induced by seismic shaking, liquefaction can also be induced by nonseismic vibration or by wave-induced shear stresses. In sufficiently loose sediments located on slopes, especially thick, very fine sands, liquefaction can be triggered by static forces alone. Such triggering mechanisms include an increased shear stress caused by toe erosion or an increased seepage force due to a changing water table. Throughout this manuscript the features attributed to a seismic liquefaction origin have fulfilled the stringent criteria presented by Obermeier (1996a), and thus there is virtually no doubt of the origin.

The shear stresses that induce seismic liquefaction are primarily due to cyclic shear waves propagating upward from bedrock and through the soil column, although waves traveling along the ground surface can be important locally. Sediment on level ground undergoes loading as illustrated in Figure 3, with the shear stresses typically being somewhat random but nonetheless cyclic. 


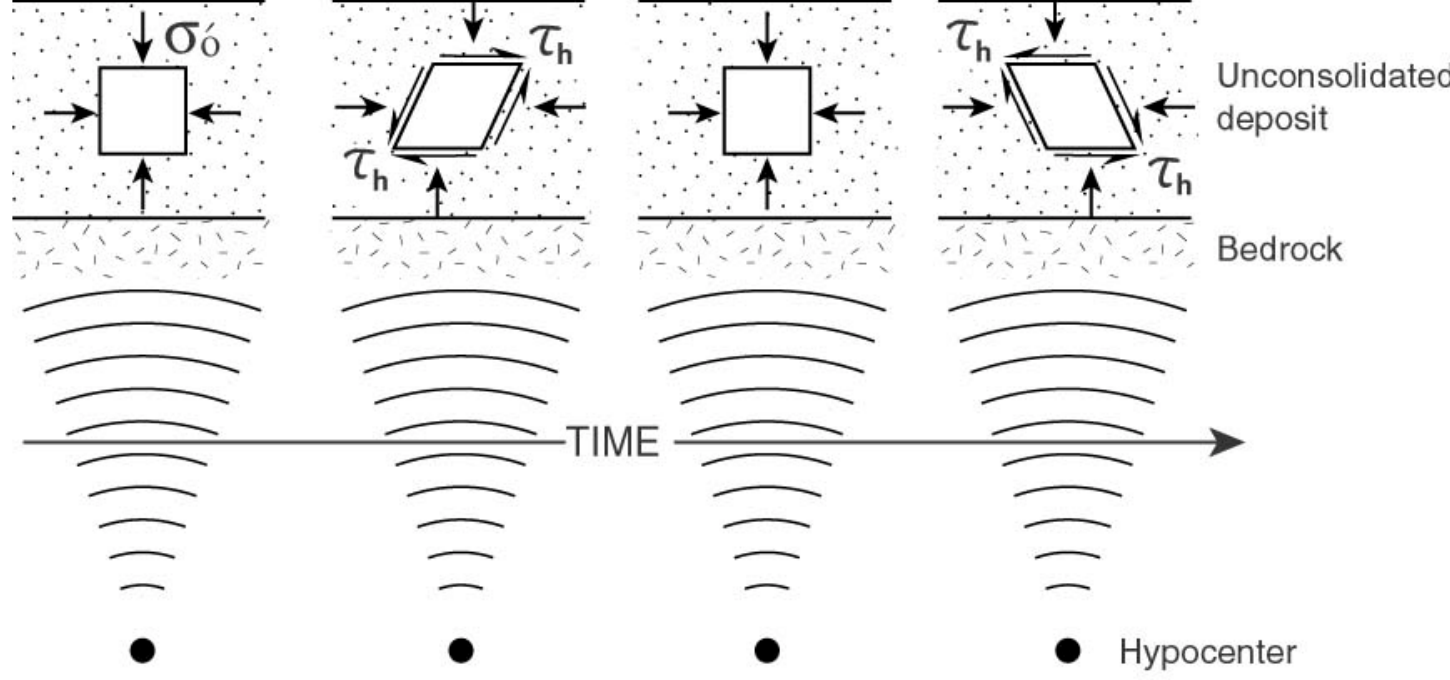


Cohesionless sediments that are loosely packed tend to become more compact when sheared. When subjected to rapid shearing (as from earthquake shaking), the pore-water does not have time to escape from the soil voids and allow the sediment to compact as the grain-to-grain skeleton is being broken down. So-called "complete" level- ground liquefaction occurs when the pore-water pressure increases enough to carry the static confining (overburden) pressure, i.e., the grain-to-grain stress equals zero and large strains and flowage of water and suspended sediment can occur. "Partial" liquefaction occurs when the increase in pore-water pressure is not enough to fully carry the static confining (overburden) pressure. Whereas, by definition, this is not true level ground liquefaction, damage and ground failure can occur under a condition of "partial" liquefaction.

The changes in the packing of grains resulting from liquefaction are illustrated in Figure 4. A large increase in pore-water pressure commonly takes place during the transition from the initial packing (Fig 4A) to that illustrated for the liquefied state (Fig 4B). The pore-water pressure in Figure 4B carries the weight of all overlying sediment and water. In many field situations, the pore-water pressure can increase several-fold within a few seconds. This large increase commonly provides sufficient excess pressure to hydrofracture a fine-grained cap lying directly above the liquefied zone.

Figure 4C illustrates the subsequent densification that occurs throughout the column of liquefied sediment during dissipation of excess pore-water pressure. Depending on the initial state of packing, large quantities of water can be expelled. The water flows upward as a result of the large hydraulic gradient, carrying along sediment. This process whereby flowing water transports sediment is referred to as "fluidization" by geologists (Lowe, 1975). The flowing water causes sediment to be carried grain-by-grain or to be dragged along by other grains. This process of fluidization transports the sediment that fills clastic dikes and sills observed in paleoliquefaction studies.

Liquefaction can result from only a few cycles of shaking or may require many cycles. For a very loose packing of sediment grains, the breakdown of grain structure can be very abrupt and liquefaction can be virtually simultaneous with the onset of shaking (e.g, Fig. 2.26 in National Research Council, 1985). Such loose packings are relatively common in delta and eolian dune deposits as well as in very young (less than 500 years) river channel deposits (Youd and Perkins, 1978). However, some very young fluvial sands have an initial packing that is so dense that any pore-water pressure increase during seismic shaking is either small or insignificant, and liquefaction never occurs (Seed et al., 1983). For older river deposits, yet still of Holocene age, the buildup of pore-water pressure generally tends to be a more gradual process and requires more cycles of shearing than for younger deposits. Deposits of Pleistocene age are very resistant to liquefaction in many field settings owing to effects of aging and weathering (Youd and Perkins, 1978). But deposits laid down hundreds of thousands of years ago and still highly susceptible to liquefaction have also been encountered over widespread areas (e.g, Obermeier et al., 1993; Martin and Clough, 1994). A broad range of susceptibilities to liquefaction typically is encountered in a field search. 


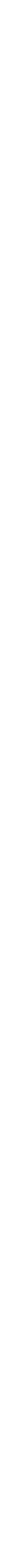




\section{Liquefaction Susceptibility}

"Liquefaction susceptibility" refers to a sediment property, and as we use the term also considers the depth to the water table and other factors in the field that affect the ability of a deposit to liquefy. The following discussion focuses on the susceptibility of sand-rich deposits because they encompass the great majority of deposits prone to liquefaction. Our use of the term "liquefaction potential" refers to the likelihood of liquefaction occurring, considering both the liquefaction susceptibility of the deposit and the specific shaking level.

The degree (relative state) of packing of sand deposits (called the "relative density" by geotechnical engineers) is a principal determinant of liquefaction susceptibility in most Holocene deposits; the relative density is, in turn, related to Standard Penetration Test (SPT) blow counts measured in-situ. Relative density is by definition a measure of how densely the sand grains are packed in comparison to the laboratory-determined loosest and densest reference states (Terzaghi and Peck, 1967). Semi-quantitative descriptions of relative density range from very loose to very dense, depending on the packing of grains. Correlations of relative density with SPT blow counts are listed in Table 1. For practical purposes, sediments having blow counts much in excess of about 30 generally are not very susceptible to liquefaction or will not liquefy, even if other factors in the field are very favorable. Loose and very loose sands are generally highly susceptible to liquefaction, and moderately compact sands are generally moderately susceptible, under favorable field settings.

Table 1. Relative density of sand as related to $\mathrm{Standard}$ Penetration Test blow counts (N) (from Terzaghi and Peck, 1967).

\begin{tabular}{cc}
\hline $\begin{array}{c}\text { No. of blows } \\
(\mathbf{N})\end{array}$ & $\begin{array}{c}\text { Relative Density or } \\
\text { Compactness }\end{array}$ \\
\hline $0-4$ & Very Loose \\
\hline $4-10$ & Loose \\
\hline $10-30$ & Medium or Moderate \\
\hline $30-50$ & Dense \\
\hline$>50$ & Very Dense \\
\hline
\end{tabular}

Liquefaction susceptibility is nearly always measured using in-situ tests because of the extreme difficulty and expense of collecting samples of sandy sediment that are sufficiently undisturbed for laboratory testing. In recent years there has been a strong tendency toward using another technique, the cone penetration test (CPT), to measure liquefaction susceptibility in-situ (e.g, Stark and Olson, 1995; Robertson and Wride, 1997). The CPT permits more detailed measurements of sediment properties and stratigraphy than does the SPT, and also likely provides 
a more accurate evaluation of in-situ liquefaction susceptibility. Use of the CPT is also relatively inexpensive compared to the SPT. Still, because of the larger database where SPT results are available, particularly in the central and eastern US, the following discussion will focus mainly on usage of that method.

SPT data commonly provide a reasonable measure of relative density in Holocene clean sand deposits. Exceptions occur where the sediment has been cemented with chemical precipitates, where the fines content (silt and clay fraction less than $0.075 \mathrm{~mm}$ ) is larger than about 15 to $20 \%$, and where the mean grain size ( $50 \%$ of the material by weight is smaller than this value) is greater than about $2 \mathrm{~mm}$. Sites where stress conditions in the sediment are unusually high in the horizontal plane can also cause misleading values of relative density from SPT readings (Terzaghi et al., 1996). A geologic situation such as glacial loading can impart high (residual) horizontal stresses.

SPT data also provide a measure of the effects of aging and weathering on liquefaction susceptibility, where chemical precipitates are not involved. Aging and weathering effects can originate from both mechanical and minor chemical (atomic-level bonding) sources (Schmertmann, 1987, 1991; Mesri et al., 1990). In the short term (of hundreds to a few thousands of years), mechanical effects caused by adjustment of grains are likely to dominate aging (Olson et al., 2001). Fortunately, the total effect of chemical and mechanical aging is almost certainly relatively minor from a practical viewpoint in some (and possibly many) field situations. For example, in glaciofluvial deposits that abound throughout the central U.S., the maximum change in SPT blow count resulting from aging is probably on the order of 3 or 4 on the basis of the difference between the loosest sediments of modern ages (with blow counts near 0 ) and the loosest deposits of early Holocene ages [data from Pond (1996) and unpublished data by Obermeier]. This change in blow count almost certainly decreases substantially with increasing initial relative density because of the diminished opportunity for mechanical adjustment of grains. The possible influence of aging and weathering effects should be evaluated on a case-by-case basis depending on the geologic setting, in view of the uncertainty of factors that determine the effects of aging (Olson et al., 2001). For example, chemically unstable minerals (such as olivine and volcanic glass) abound in the sediments in some parts of the western U.S and their effects may be important in the short term, in contrast to the central and eastern U.S.

\section{Field Conditions Favorable for Formation of Liquefaction Features}

Liquefaction can occur but leave behind no clear-cut evidence within the bed that liquefied. Indeed, in nearly all field searches liquefaction is indicated by out-of-place cohesionless sediment cutting through a finer-grained host, forming clastic dikes and sills such as those illustrated in Figures 1 and 2. Dikes and sills form most readily where a thick, sand-rich deposit is capped by a low permeability deposit and the water table is very near the ground surface. Grain sizes that are generally the most prone to liquefy and fluidize range from silty sand to gravelly sand A thickness of one meter of liquefied sediment generally suffices to form recognizable clastic dikes, although a much smaller thickness can be adequate depending on factors such as the severity of liquefaction, the local field setting, and the mechanism that forms the dikes. All these factors are later discussed in detail. 
For the normal range of Holocene sediments encountered in a river valley, clastic dikes readily cut entirely through a cap having a thickness on the order of a meter, and can cut through a much greater thickness where shaking and liquefaction have been severe (Ishihara, 1985; Obermeier, 1989). Field observations show that clastic dikes readily form in caps having consistencies ranging from very soft (soft enough to force the thumb into the cap hosting the dike) to stiff (requiring effort to crush a piece of soil between the thumb and finger). (See Terzaghi et al., 1996, p. 22, for relations between consistency and compressive strength of clays.) In addition, dikes have been observed to have formed in hard, massive, silt and clay-rich glacial tills (too strong to be crushed between the fingers).

Liquefaction typically occurs at shallow depth. Depths of liquefied source beds most commonly reported are less than a few tens of meters (e.g, Seed, 1979). Paleoliquefaction searches by Obermeier (co-author) in diverse field settings throughout the U.S., where the water table was probably between one and five meters deep at the time of the earthquake, show that dikes are found most often in fine-grained caps that are one to five meters in thickness. Caps thicker than 10 meters only exceptionally host dikes, including small dikes along the base of the cap. Most likely, the paucity of dikes in thicker caps is because greater depths require exceptionally severe shaking for an occurrence of liquefaction. Liquefaction beneath thicker caps is unlikely because the increasing overburden pressure can increase the shear resistance of a cohesionless sediment beyond the shear stress induced by seismic shaking.

Effects of liquefaction are most pronounced where the water table lies within a few meters or less of the surface. Where the water table is five meters or deeper, the overall effects of liquefaction are diminished but locally can still be severe, with dikes up to $0.6 \mathrm{~m}$ wide formed during shaking as low as $0.2-0.3 \mathrm{~g}$ (e.g., Pond, 1996). A change in water table depth from the surface to a depth of $10 \mathrm{~m}$ can change the ability of a deposit to liquefy from high to nil, respectively (e.g, see Table 4-1 in National Research Council, 1985). Further discussion of the influence of depth of water table is deferred to a later section, because of the need to first discuss the various mechanisms that form liquefaction features.

\section{Mechanisms that Form Liquefaction Features}

Dikes in a fine-grained cap are induced chiefly by three ground-failure mechanisms: hydraulic fracturing, lateral spreading, and surface oscillations. These three mechanisms can occur independently or in combination with one another. Seminal articles discussing lateral spreading and surface oscillations include Bartlett and Youd (1992), Youd and Garris (1995), and Pease and O'Rourke (1995). The major role of hydraulic fracturing in response to seismic liquefaction was first deduced by Obermeier (1994), following discussion of the process in the failure of earth dams by Lo and Kaniaru (1990).

The various ground-failure mechanisms. Hydraulic fracturing initiates at the base of a finegrained cap sitting on liquefied sediment. Fracturing of the cap typically occurs in response to the high pore-water pressure entering naturally occurring flaws along the base of the cap, such as small root holes and other tubes. The pressure causes vertical, tensile fractures that are tabular in plan view to develop; these fractures then are filled with a fluidized mixture of sand and water that is 
driven by the hydraulic gradient. Similarly, vertical tabular defects in the cap that formed by weathering can be opened by the high pore-water pressure, leading to the formation of tabular dikes. In many field settings the dikes are mainly parallel to one another, but where liquefaction has been severe they can also develop in an irregular, nearly haphazard pattern in both plan and sectional views. Dikes from hydraulic fracturing are typically quite narrow, ranging from a few millimeters to less than $10 \mathrm{~cm}$ wide.

Lateral spreads reflect translational movement downslope or toward an unrestrained face such as a stream bank. The movement occurs where there is only minor resistance to lateral translation of the fine-grained cap sitting on liquefied sediment. The effects are manifest as tabular clastic dikes, which have a strong tendency to parallel the unrestrained face or the slope contours. Dikes originating from lateral spreading, and especially the wider dikes, are the result of fluidized sand and water flowing into breaks through the cap that have been opened by shaking and/or downslope gravity forces due either to the slope of the ground surface or the slope of the liquefied zone along the base of the cap (Bartlett and Youd, 1992). Dikes associated with lateral spreading are commonly quite wide. Dikes can be as much as 0.5 to $0.7 \mathrm{~m}$ in width even where shaking has been only moderately strong (say, about $1 / 4 \mathrm{~g}$ ). Widths of as much as a few to several meters are not unusual where shaking has been very strong.

Lateral spreads are typically defined as occurring on slopes of three degrees or less (Youd and Garris, 1995). On steeper slopes, liquefied deposits can flow tens of meters to a kilometer (Tinsley et al., 1985). Such deposits are rarely observed within the broad alluvial valleys that are typical of the types of field settings that are being considered in this paper, and thus are not within the scope of this paper.

Surface oscillations can cause tabular clastic dikes to originate in response to the fine-grained cap being strongly shaken back and forth above liquefied sediment. We use the term "surface oscillation" as a generic description of an end effect rather than a driving mechanism. This definition is in the sense commonly used by geotechnical engineers to describe liquefaction-related ground failure that requires, in plan view, large back-and-forth straining of the cap; high accelerations may or may not be involved. Indeed, during strong bedrock shaking at sites of liquefaction, the accelerations in the cap can be de-amplified to a lower level even as straining of the cap is greatly augmented and breaks apart the cap (e.g, see analysis in Pease and O'Rourke, 1995). Surface oscillations can originate from either body (S) waves (Pease and O'Rourke, 1995) or surface waves (Youd, 1984). The back-and-forth straining in the cap can be in the form of either axial or shear strains (Pease and O'Rourke, 1995, Fig. 2-1). Rayleigh waves are likely involved at sites of severe axial straining, and either S- or Love-waves are likely involved at sites of severe shear straining. The effects of Rayleigh waves are probably best manifested by dikes that tend strongly to parallel one another with a spacing that can range from tens to hundreds of meters apart; these effects are generally most severe in the meizoseismal zone but can also extend far beyond (T.L. Youd, Brigham Young Univ., 1998, oral commun.). Surface oscillations from what are likely to have been Rayleigh waves are often seen by observers as traveling ground waves. Dike widths from surface oscillations may be as much as $15 \mathrm{~cm}$ (T.D. O'Rourke, Cornell Univ., 1998, written commun.). Sites of severe shear straining may be indicated by lateral offsets along dikes and along fractures at the ground surface. Little is known about relations between 
surface oscillations and ground failure, especially involving shear strains at the surface, and this is probably a fruitful area for research in paleoseismology.

The three mechanisms noted above generally are dominant in producing the larger dikes, especially tabular dikes visible at the ground surface. However, liquefaction can also leave behind small tubular clastic dikes in a fine-grained cap. Small tubular dikes (as much as a few centimeters in diameter) and irregular dikes commonly develop in plan view where venting has taken place through an extremely soft or friable cap (see the photograph of Fig. 23D in Obermeier, 1996a). Also, small tubular dikes can develop in pre-existing holes left behind by decayed roots and in holes excavated by creatures such as crabs or crawfish (Audemard and de Santis, 1991).

Factors controlling the mechanism of ground failure. Different levels of shaking are required to form dikes visible at the ground surface for each of the mechanisms of lateral spreading, surface oscillations, and hydraulic fracturing. For cohesionless deposits that are very loose to moderate in relative density (Table 1), lateral spreads typically occur farthest from the meizoseismal region (providing a stream bank is nearby at the time of the earthquake). The factors that determine their most distant occurrence have not been verified, but could be due to a stream bank offering little or no resistance to lateral movement during shaking, or could be due to facts that the youngest deposits typically border a stream and the water table is commonly shallow there. Dikes from surface oscillations (Youd, 1984) can also develop considerably beyond the meizoseismal zone, especially where conditions are favorable for developing surface oscillations from surface waves (e.g, broad valleys, alluvium at least tens of meters in thickness, and flat-lying bedrock). Dikes from surface oscillations are likely developed from S-waves far beyond the meizoseismal zone, even at sites of marginal liquefaction and relatively low accelerations, because of the tendency for surface oscillations to develop for S-wave vibrations with longer periods (Pease and O'Rourke, 1995). In most field situations with settings of moderate liquefaction susceptibility, hydraulic fracturing seems to cause only small, scattered dikes to form beyond the meizoseismal zone, even for earthquakes in excess of $\mathbf{M} \sim 7$.

Field relations showing the relative influence of lateral spreading and hydraulic fracturing in the formation of dikes are illustrated in Figure 5. The formation of dikes from lateral spreading predominates near the stream bank, and effects from hydraulic fracturing become predominant with increasing distance from the bank. Figure 5 shows relations that are observed commonly and illustrates formation of dikes above liquefied sands of medium density. Relations in Figure 5 are for sites where liquefaction has not been very severe and the influence of hydraulic fracturing is not very strong. Farther from the meizoseismal zone, the influence of hydraulic fracturing is often minor and relations shown in Figure 5B are observed at many places.

The thickness of cap that is penetrated by hydraulic fracturing probably depends primarily on the thickness of sand that liquefies, as shown in Figure 6, because this liquefied thickness controls the magnitude of pore-water pressure increase as well as the volume of water expelled. The penetrated cap thickness is also strongly dependent on the severity of ground shaking (i.e., peak surface acceleration). The relations in Figure 6, first proposed by Ishihara (1985), appear to be valid for earthquakes of $\mathbf{M} \sim 7.5$ and stronger in that the procedure predicts conditions where surface effects 

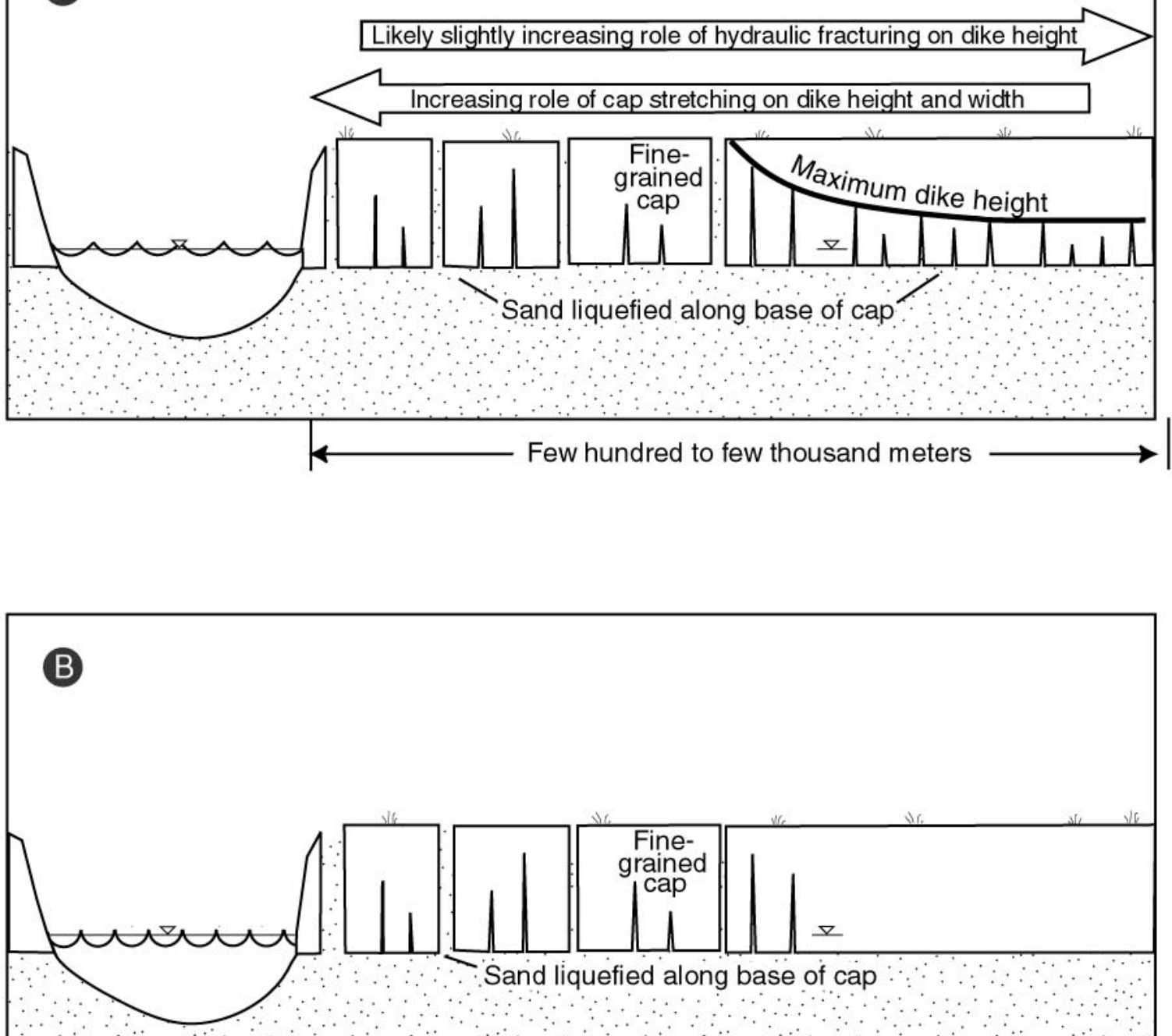

M.

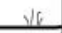


both will and will not occur (e.g, see Youd and Garris, 1995). Youd and Garris (1995) also found that dikes caused by hydraulic fracturing commonly have much lesser heights than those formed by lateral spreading or surface oscillations. The maximum thickness of cap that has been observed to be ruptured by hydraulic fracturing is about $9 \mathrm{~m}$ (see Fig. 6). No data are available concerning the strengths of caps that can be ruptured by hydraulic fracturing, but unpublished data by Obermeier show that this mechanism commonly develops in caps having a relatively wide range of consistencies, varying from soft to firm. (It should be noted that Youd and Garris, 1995, state

only that the relations in Figure 6 are not valid for lateral spreading or surface oscillations; by the process of elimination, we attribute the mechanism primarily to hydraulic fracturing.)

The maximum cap thickness that can be ruptured by lateral spreading is commonly much greater than from hydraulic fracturing (see Fig. 3 in Youd and Garris, 1995). The maximum that has ever been documented is about $16 \mathrm{~m}$ (T.L. Youd, Brigham Young Univ., 1997, oral commun.). In many field settings the maximum thickness is probably controlled by the maximum depth of liquefaction; this is because of the low tensile strength of the cap in relation to the stresses imposed on the cap by gravity and seismic shaking. Caps of Holocene and late Pleistocene ages composed of silt and clay sediments typically have very low tensile strengths, and thus are easily pulled apart by lateral spreading. Dikes probably caused by lateral spreading have been observed by Obermeier (co-author) in the central U.S., even at sites where clay-rich caps have been compacted to a hard consistency by glacial loading, although the level of shaking required for formation of these dikes was likely very high.

The formation of lateral spreads is not nearly as dependent on the thickness of the liquefied zone as is hydraulic fracturing. Lateral spreads have been observed to form on liquefied sand strata only a few centimeters in thickness (J.R. Keaton, AGRA Inc., Phoenix, Arizona, 1993, written commun.). Lateral continuity of the liquefied bed is especially important for lateral spreading, particularly on such a thin stratum.

The thickness of cap ruptured by surface oscillations commonly is greater than by hydraulic fracturing (Youd and Garris, 1995), and the effects of surface oscillations tend to extend much farther from the meizoseismal zone. In general, though, breakage of the cap by surface oscillations is quite localized away from the meizoseismal zone, even for a very large earthquake.

No data are available concerning the role of thickness of liquefied sediment on development of surface oscillations, although we suspect that a meter or more suffices for typical fluvial sands, at least near the meizoseismal region of a very large earthquake. This tentative suggestion is based on our field observations in the Wabash Valley of Indiana-Illinois. Preliminary unpublished data by Obermeier (co-author) also indicate that parallel joints in the cap can develop from seismic shaking, even where no liquefaction has occurred, providing that shaking has been strong enough. (Joints from other mechanisms such as weathering and desiccation are commonly much more haphazard and discontinuous than those of seismic origin.)

In the previous section it was noted that formation of liquefaction features depends on depth to the water table. The influence of water-table depth seems to be very dependent on the mechanism that is primarily responsible for rupturing the cap. Unpublished data by Obermeier (co-author) 


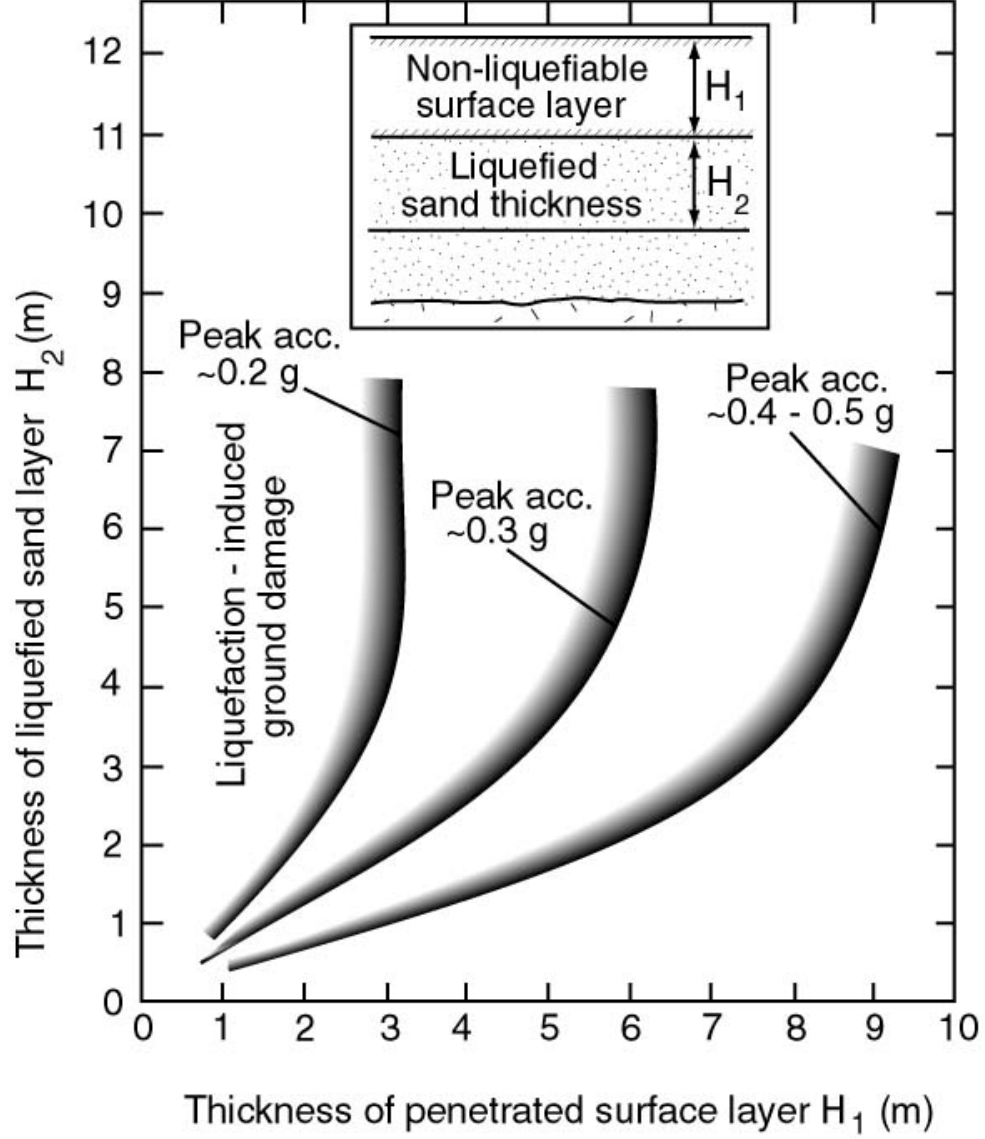

Figure 6. Thickness of cap penetrated by hydraulic fracturing, as related to thickness of liquefied sand and peak surface accelerations. Modified from Ishihara (1985). 
indicate strongly that cap breakage by hydraulic fracturing can be much more sensitive to depth of the water table than is cap breakage by lateral spreading. No data are available for surface oscillations, but we anticipate that cap breakage due to this mechanism requires that the water table is at or near the base of the cap, unless shaking was particularly severe.

Field Examples of various manifestations of liquefaction. Evidence of the three dominant liquefaction-related ground failure mechanisms is apparent in aerial photographs of the meizoseismal zone of the great 1811-12 New Madrid (Missouri) earthquakes (Fig 7). Within a time span of only three months, numerous strong earthquakes struck along a more than $175-\mathrm{km}-$ long fault zone. One was probably at least $\mathbf{M} 8$ and two more were nearly as large (Johnston and Schweig, 1996). The earthquakes were centered beneath a huge region of liquefiable deposits, causing tremendous liquefaction. Sand that vented to the surface formed a veneer more than 0.5 to $1 \mathrm{~m}$ in thickness over hundreds of square kilometers. More than 1 percent of the ground surface was covered by vented sand over thousands of square kilometers (Obermeier, 1989). The meizoseismal zone of the 1811-12 earthquakes is one of the best in the world to see the effects of liquefaction in sectional view, which is very useful for paleoliquefaction studies. The sectional, or vertical, view permits viewing of dikes that pinch together and never reached the surface, and also permits viewing of dikes that were later buried by sediments or have been weathered so severely as to not be observable at the surface.

Figures $8 \mathrm{~A}$ and $8 \mathrm{~B}$ are aerial photographs from the meizoseismal zone of the 1811-12 earthquakes. These photographs illustrate the effects of lateral spreading, hydraulic fracturing, and probably surface oscillations. Fissuring and venting took place in braid-bar deposits of latest Pleistocene age and in Holocene point-bar deposits. The ground surface is quite flat, overall, except at stream banks that typically are only several meters high. The light-colored portions of the photos show sand vented to the surface. The dark background is the dark-colored, clay-rich cap onto which the sand vented. The light-colored linear features are long fissures through which sand vented, and the light-colored spots are individual sites of venting. Venting occurred through dikes, as illustrated in Figure 1.

Note the abundance of linear fissures that are more or less parallel to one another in the upper right side of the photo of Figure 8A. These fissures are of lateral spreading origin and formed near a break in slope. The photo clearly shows that lateral spreading in this area was severe at distances farther than half a kilometer from the stream. Individual sand blows, which are particularly well expressed in the upper left part of the photo, formed by hydraulic fracturing. An origin of hydraulic fracturing is clearly indicated by the random "shotgun pattern" of the sand blows.

Hydraulic fracturing can also follow geologic details, as illustrated in the lower right portion of the photograph of Figure 8A. Sand blows here developed in point bar deposits, as illustrated by the arcuate bands of vented sand The venting occurred along the crests of scrolls of point bar deposits, where the cap is thinnest (Saucier, 1977). A venting origin to the sand is demonstrated by the irregular, jagged patterns of sand along the arcuate bands, which precludes the possibility of the sand being visible at the surface simply because of the absence of a fine-grained cap along the crest of the scroll.

The development of lateral spreads and individual sand blows shown in Figure 8 is typical of that 


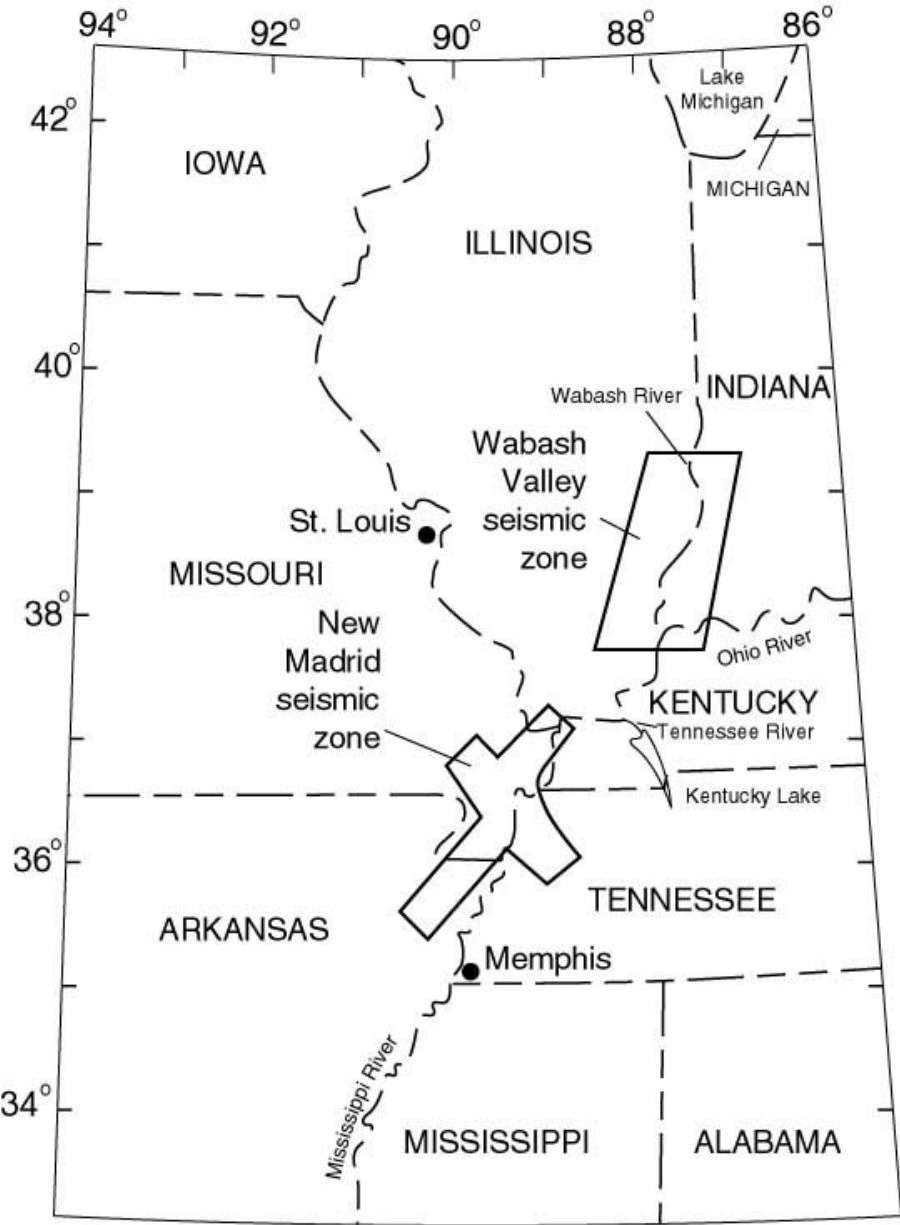

Figure 7. Approximate limits of New Madrid Seismic Zone anc Wabash Valley Seismic Zone. New Madrid Seismic Zone is the source area of the great New Madrid, Missouri, 1811-12 earthquakes; the region continues to have many small and some slightly damaging earthquakes. Wabash Valley Seismic Zone is a weakly defined zone of prehistoric seismicity having infrequent small to slightly damaging historic earthquakes. 

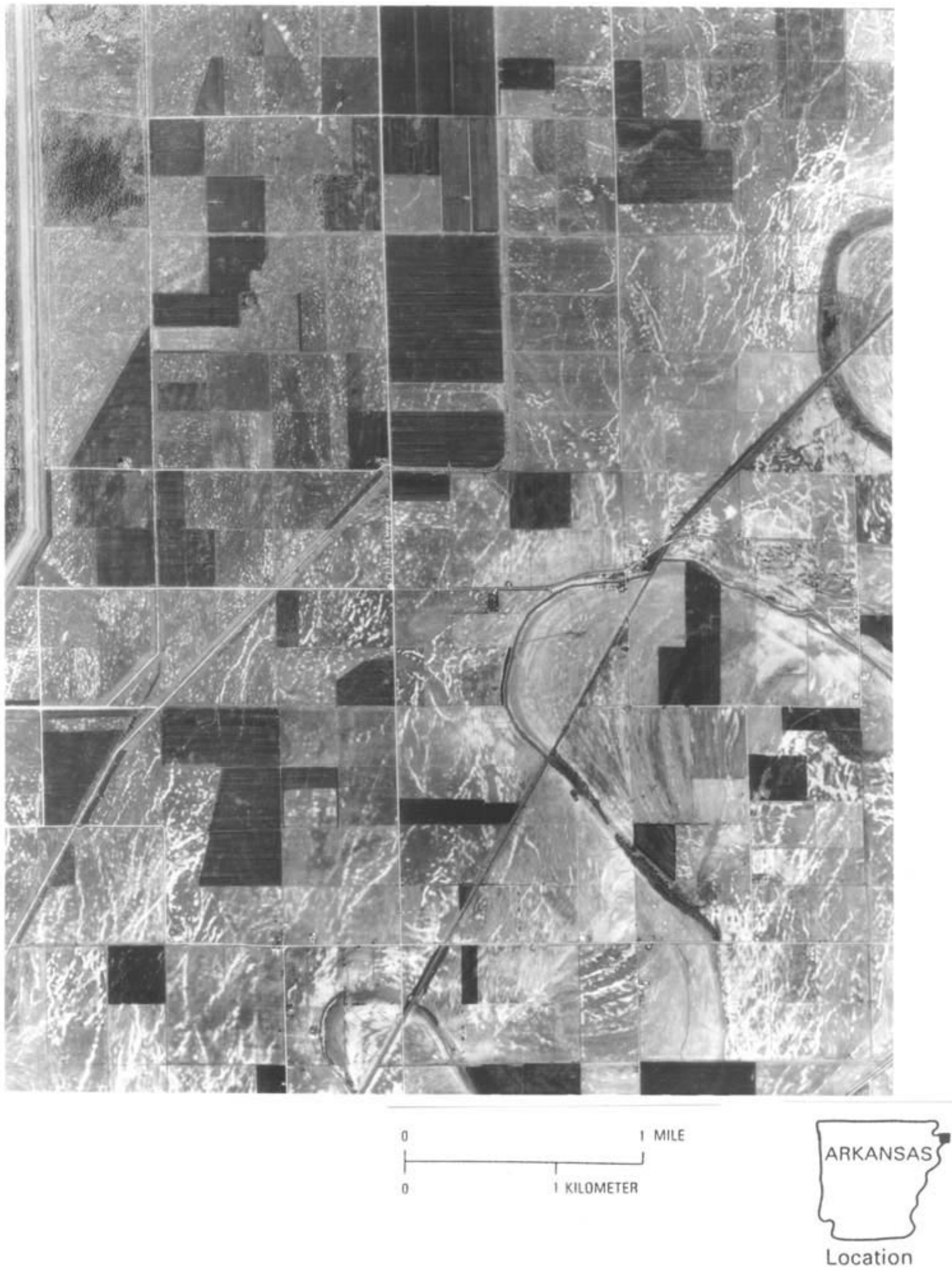

Figure 8. (A) Aerial photograph showing effects of severe liquefaction in the meizoseismal zone of the great 1811-12 New Madrid (Missouri) earthquakes. White linear features show sand that has vented through breaks in the cap caused by lateral spreading. Note the concentration of linear breaks in proximity to stream banks. Isolated white spots show sand that has vented through breaks in the cap caused by hydraulic fracturing. Photograph location shown on outline of state of Arkansas. 
throughout the meizoseismal region of the1811-12 New Madrid earthquakes, in that the dikes from lateral spreading commonly extend a large distance (even more than a kilometer) from any breaks in slope, and the isolated sand blows developed throughout the area, independent of proximity to a stream bank.

The fissures in the central part of Figure 8B appear to have formed chiefly from surface oscillations related to Rayleigh waves. This origin is the preferred interpretation because the fissures are more or less parallel to one another (indicating a tensile fracturing of the cap), and they have developed on very flat lying ground that seems too far from any banks to be associated with lateral spreading. There also is no evidence of lateral spreading in proximity to the abandoned stream course, in the upper right portion of the photograph. Hydraulic fracturing alone did not induce the fissures because they are too long too strongly developed, and do not follow any depositional traits (i.e., inherent weaknesses) of the cap.

There is a widespread perception that wide dikes that form by lateral spreading are restricted to areas very near stream banks. However, in the meizoseismal region of the 1811-12 New Madrid earthquakes, dikes from lateral spreading as large as $0.5 \mathrm{~m}$ in width are plentiful even hundreds of meters from any significant slopes. In another example, in the Wabash Valley of Indiana-Illinois, within the meizoseismal zone of a prehistoric $\mathbf{M} \sim 7.5$ earthquake, dikes up to $0.5 \mathrm{~m}$ in width probably formed hundreds of meters from any stream banks when the earthquake struck (Munson and Munson, 1996; Pond, 1996; Obermeier, 1998a).

In both the New Madrid and Wabash regions, liquefaction susceptibility is only moderate at most places (Obermeier, 1989; Pond, 1996), and is probably typical of medium-grained, moderately well-graded fluvial deposits elsewhere. Data from a worldwide compilation of historical earthquakes by Bartlett and Youd (1992) clearly show that horizontal movements of a few to several meters commonly extend hundreds of meters back from stream banks, especially where seismic shaking has been very strong; we believe that wide dikes far from the banks should also be expected for these field and seismic conditions.

The probable explanation for the exceptional development of lateral spreading from the 1811-12 New Madrid earthquakes is that there were very high levels of shaking, which were caused by high stress drops in bedrock at depth (Hanks and Johnston, 1992). A major point of relevance, indicated in Figure $8 \mathrm{~A}$, is that the severity of lateral spreading, including the distance of development from stream banks, can be an indicator of the severity and duration of strong shaking.

\section{W HERE W AS THE SO URC E REGIO N?}

Verification of a seismic origin to suspected liquefaction features typically involves demonstrating that (1) details of individual clastic dikes conform with those of known seismic origin, (2) both the pattern and location of dikes in plan view conform with a seismic origin, on a scale of tens to thousands of meters, (3) the size of dikes on a regional scale identifies a central "core region" of widest dikes, which conforms with severity of effects expected in the energy source region (the meizoseismal zone), and (4) other possible causes for the dikes, such as artesian conditions and landsliding are not plausible (Obermeier, 1996a; 1998a). The following discussion describes how 
to identify the core region.

As we use the term "core region," we are referring to the region of strongest bedrock shaking. We also refer interchangeably to this region throughout the paper as the "source region" or as the "energy center." We have used two methods to estimate the source region in the Wabash Valley. Both methods have widespread applicability for paleoseismic studies. One involves a direct measurement of dike widths and the other involves back-calculating the strength of shaking. Both require collecting data over a large region in order to see a clear-cut trend in the data. In practical terms, for an $\mathbf{M} 6$ to 7 earthquake, data must be collected over an area of several to many tens of kilometers in radius. Preferably, data are collected from the region of distal effects of liquefaction, where dikes are small (narrow) and sparse, to the area close to the source region where dikes are much larger (wider) and more plentiful.

Dike width serves as a superior parameter to locate the source region in many field settings (Obermeier, 1996a). This width generally reflects the amount of lateral spreading except where dikes are relatively small (say, less than $10 \mathrm{~cm}$ wide). Conceptual verification for using dike width to locate the source region is provided from a study of historical earthquakes by Bartlett and Youd (1992). Dike width works well because the development and magnitude of lateral spreading is largely independent of thickness and strength of the cap, at least for sediments that are typical of Holocene and late Pleistocene ages. Either maximum dike width or the sum of dike widths at a site appears to work equally well to estimate the source zone (Munson et al., 1995). A valid interpretation based on the width of dikes obviously requires that bank erosion has not been so severe as to have destroyed dikes from lateral spreading. Problems of interpretation due to erosion are generally not serious in the meizoseismal zone of a very large-magnitude earthquake because of the tendency for large lateral spreads to develop even relatively far from the stream banks.

Data from historical earthquakes in the Wabash Valley region (Fig 7), in the forms of Modified Mercalli Intensities and instrumentally-located epicenters (Rhea and Wheeler, 1996), suggest that using liquefaction features to locate the source region of prehistoric earthquakes is generally accurate within a few tens of kilometers, at least for earthquakes of moderate size. The uncertainty in location probably increases with increasing magnitude because of the tendency for the epicenter of larger earthquakes to be farther removed from the area of strongest shaking (e.g, Youd 1991). Still, it appears that the distribution and severity of liquefaction effects can be used to reasonably estimate the region of strongest bedrock shaking (Pond, 1996).

Other parameters such as the density of dikes per unit length and density per unit area have been used by other researchers in their attempts to locate the region of strongest shaking. There are numerous practical problems in trying to interpret the data using such an approach, however, because dike density is controlled by different factors for each of the mechanisms of lateral spreading, surface oscillations, and hydraulic fracturing. In many field situations it is impossible to determine which mechanism(s) controlled the density of dikes. Interpretations can be questionable without such a differentiation.

Back-calculation of the strength of shaking at widespread sites can sometimes be used to better locate the source region where dike-width data are sparse. This back-calculation procedure has 
been verified by comparing this interpretation with that of the dike-width method that was discussed above; both yielded the same results (Pond, 1996). (The method for back-calculating the strength of shaking is discussed in a subsequent section.)

A question that is often asked is whether paleoliquefaction features resulted from a single large earthquake or from a series of small earthquakes that were closely spaced in time. The answer is generally best resolved by analysis of the regional pattern of dike widths. The attenuation pattern of maximum dike widths around a core region should be examined in orthogonal coordinates (preferably along the suspected fault axis and perpendicular to the axis). A monotonic decrease of maximum dike width in orthogonal directions around the suspected core indicates a single large earthquake. In the Wabash Valley, this approach was verified by geotechnical back-calculations of the prehistoric strength of shaking for four prehistoric earthquakes (Pond, 1996). The use of dike widths alone to resolve the issue of the number of events requires that the liquefaction susceptibility be reasonably uniform on a regional basis and also that the amplification or attenuation of bedrock motions be similar on a regional basis. Where these conditions are not met, calculations of site-specific response to bedrock shaking can sometimes resolve the issue (Pond, 1996).

To answer the question of whether a single or multiple earthquakes caused the observed features, the methods described above usually work best for very large earthquakes because of the tendency for the regional pattern of liquefaction features to become more conspicuous with increasing magnitude. For example, the regional pattern of dike sizes and abundance, in conjunction with radiometric dating, has been used in coastal South Carolina to show that liquefaction effects from prehistoric earthquakes were caused by very large earthquakes rather than multiple small earthquakes closely spaced in time (Obermeier, 1993; Obermeier, 1996a). More recently, using basically the same logic, the regional pattern of severity of venting has been used to evaluate whether paleoliquefaction features discovered within the meizoseismal region of the great 181112 New Madrid earthquakes were from a few very large earthquakes rather than a series of much smaller earthquakes (Tuttle, 1999). The New Madrid region is nearly ideal for this type of analysis because the liquefaction susceptibility is remarkably uniform over a huge area, the causative fault system for major earthquakes is likely known, and the regional pattern and extent of liquefaction from the 1811-12 earthquakes has long been known reasonably well.

Using the paleoliquefaction method for determining the timing and strength of shaking of various earthquakes, within a relatively small region, works best where the large earthquakes are spaced apart sufficiently in time to distinguish different generations of liquefaction features from one another. The techniques for sorting these generations have been developed mainly in a classic study in the Wabash Valley region by Munson and Munson (1996). Their approach is well suited for many field settings and typically uses radiocarbon dating, depth of weathering, pedology, sediment stratigraphy, and archeological artifacts, in conjunction with the regional pattern of sizes of liquefaction features. They also were the first to note that sand deposits that had been vented to the surface were especially valuable as sites for narrowly bracketing when liquefaction occurred; the vented sands typically formed slightly elevated, dry places in lowland areas that otherwise were wet and muddy much of the year. The vented sand deposits were much frequented by Native Americans, who commonly left behind hearths and artifacts on the vented sand that can be used for dating. 


\section{DID S TRONG SHAKING O CCUR W ITHO UT LEAVING LIQ UEFAC TION EVIDENCE?}

There is a common perception among geologists and engineers that liquefaction can occur in a region but leave behind no evidence. Our response to that perception is yes - and no. Discovering effects of liquefaction in a field search is usually easy where liquefaction has been severe throughout a region but may be difficult where liquefaction has been marginal or highly localized. Below we present some of the major factors that determine the severity of liquefaction.

\section{Effects of Strength of Shaking and Liquefaction Susceptibility}

The discussion below relates occurrence and severity of liquefaction effects to Modified Mercalli Intensity (MMI). This approach is used because MMI correlates strongly with both severity of liquefaction and damage to man-made structures (Wood and Neumann, 1931). MMI also correlates reasonably well with peak surface acceleration (Krinitzsky and Chang, 1988). Seed et al. (1985) report similar correlations developed in China for $\mathbf{M} \sim 7.5$ earthquakes. The Chinese correlations (Table 2) emphasize higher earthquake magnitudes than those of Krinitzsky and Chang (Table 2), whose relations are for a much wider range of magnitudes. Relations below by Krinitzsky and Chang (1988, Fig. 7) are for sites at the "far field," which are removed from the region of strongest shaking.

Table 2. Correlations between Modified Mercalli Intensity (MMI) and peak surface acceleration.

\begin{tabular}{ccc}
\hline & \multicolumn{2}{c}{ Peak Surface Acceleration $\left(\mathbf{a}_{\text {max }}\right)$} \\
\cline { 2 - 3 } MMI & Chinese & Krinitzsky and Chang (1988) \\
\hline VII & $\sim 0.1 \mathrm{~g}$ & $\sim 0.13 \mathrm{~g}$ \\
VIII & $\sim 0.2 \mathrm{~g}$ & $\sim 0.2 \mathrm{~g}$ \\
IX & $\sim 0.35 \mathrm{~g}$ & no data \\
\hline
\end{tabular}

Throughout the meizoseismal region of a very strong earthquake, in which the MMI value is IX or higher, liquefaction features should abound even where the liquefaction susceptibility is only moderate (as defined previously and below). Any reasonable effort to locate numerous liquefaction features should be successful. Some wide dikes almost certainly exceeding $0.3 \mathrm{~m}$ and many small dikes should be discovered.

For moderate liquefaction susceptibility in regions of MMI VII-VIII, small liquefaction features may be sparse but still should be numerous enough that some features would be discovered during the examination of tens of kilometers of stream banks. 
Moderate liquefaction susceptibility implies medium relative density (Table 1) as well as a water table within several meters of the surface and a cap thickness less than 8 or 9 meters. Moderate liquefaction susceptibility is about the norm for deposits of latest Pleistocene and Holocene ages that have been laid down by moderate to large streams in the central and eastern U.S. (We have insufficient data to comment about the western U.S.) This level of susceptibility applies to streams of both glaciofluvial braid-bar and Holocene point-bar origins. A lower limit of moderate susceptibility requires a bed of silty sand, sand, or gravelly sand (generally less that about 40 percent gravel) that is at least a few to several meters thick, and the bed should be capped by at least a half a meter or more of sediment having lower permeability. Where a cap is underlain by medium-grained sand or coarser sediment, the water table should be at or above the base of the cap at the time of the earthquake; otherwise, unless liquefaction occurs through a large thickness of sediment and has made available a large quantity of water, the high permeability of the material beneath the cap can permit dissipation of pore-water pressure induced by shaking, leaving no evidence of the occurrence of liquefaction.

Still, it is not unusual that source beds much thinner than a few meters produce liquefaction features. Where shaking is strong enough (exceeding $0.2 \mathrm{~g}$ ) during a very large earthquake $(\mathbf{M}>7.5)$, a liquefied sand thickness of only $1 \mathrm{~m}$ or less should suffice to develop dikes in response to hydraulic fracturing, at least for a cap that is not exceptionally thick. Even a liquefied thickness of $0.3 \mathrm{~m}$ can suffice for this severity of shaking. Such a thickness of liquefiable sand is commonly found at the top of glaciofluvial gravel and cobble beds, directly beneath a fine-grained cap. For this field setting, and with a water table depth of less than about two meters, dikes have been found to develop within the meizoseismal zone of a $\mathbf{M} \sim 7$ earthquake, at least in the central U.S. (e.g, Pond, 1996).

\section{Effect of Grain Size}

Tsuchida (1970) recognized that the formation of liquefaction features predominates in sands containing little or no gravel or fines, with uniform fine clean sands being most susceptible to liquefaction. Since 1970, liquefaction features have been documented in nearly all cohesionless soils, including sandy gravels, silty sands to sandy silts, cohesionless silts, and tailings sands and slimes.

Gravelly sand and sandy gravel with as much as $60 \%$ gravel content (and perhaps even more) can liquefy and form large dikes during earthquakes for the conditions of strong shaking, impeded drainage, and a water table near the ground surface (Meier, 1993; Yegian et. al. 1994). It appears that the presence of a fine-grained cap controls the formation of liquefaction features in gravel-rich deposits (i.e., deposits in which individual gravel particles are generally not encased in a sand matrix). Liquefaction features have been observed both historically (Harder and Seed, 1986; Andrus, 1994; Yegian et al., 1994) and prehistorically (Pond, 1996) in gravelly soils with caps. Even a thin fine-grained cap can suffice to impede drainage and allow the pore-water pressure to increase during shaking, but it seems likely to us that the areal extent of the cap also needs to be large. Earthquake magnitudes of $\mathbf{M} \sim 7$ to 7.5 and shaking levels lower than 0.4 to $0.5 \mathrm{~g}$ were adequate to trigger liquefaction in the many of the cases cited above. However, very gravel-rich deposits without fine-grained caps can withstand strong 
shaking (on the order of 0.5 to $1.0 \mathrm{~g}$ ) without forming liquefaction features (Yegian et al., 1994).

Back-analysis of liquefaction cases involving gravelly soils is complicated because of the effect of gravel on the measurement of penetration resistance. Tokimatsu (1988) showed that the penetration resistance of soils even with only a small percentage of gravel can be artificially increased compared to that of a clean sand at the same relative density and confining pressure, because of the large size of the gravel particles with respect to that of the penetration equipment. Tokimatsu (1988) tentatively suggested a reduction factor to correct the SPT blow count of gravelly soils (based on mean grain size) to that of a sand for use in liquefaction analyses. However, the application of such a correction factor incorporates considerable uncertainty in any back-analysis.

Cohesionless silt will also liquefy and fluidize to form dikes, sometimes extensively (Youd et al., 1989). "Dirty" sands containing as much as $85 \%$ fines (silt and clay) have been observed to liquefy (Bennett 1989), but soils with more than 15 to $20 \%$ clay content $(<0.005 \mathrm{~mm})$ are unlikely to liquefy (Seed et al. 1983). The effect of fines on liquefaction susceptibility has not been completely resolved, and numerous apparently conflicting data and opinions exist in the literature. The effect of fines on liquefaction potential can be separated into two categories: (1) effect on liquefaction resistance of the soil, and (2) effect on penetration resistance.

Recent studies have indicated that the effect of fines on liquefaction susceptibility depends on the nature of the fines (i.e., plasticity and cohesion). Cohesionless silts (e.g., tailings slimes) and some sands with cohesionless silt contents as high as $30 \%$ may be more susceptible to liquefaction than clean sands (Ishihara 1993; T.L. Youd, Brigham Young Univ., 1997, written commun.). In addition, Yamamuro and Lade (1998) noted that at low overburden pressures, uniformly-sized sand with a low cohesionless silt content (perhaps less than 10 percent) is more likely to "collapse" and liquefy than the same sand containing no silt; Yamamuro and Lade hypothesized that the silt grains cause the silty sand to form a more "honeycombed" structure during deposition compared to a clean sand, even at the same global relative density. This causes the silty sand to be more susceptible to collapse and pore-water pressure increase upon shearing.

Field observations vary concerning the influence of silt content on the formation of liquefaction effects. In the western U.S., M.J. Bennett (U.S. Geol. Survey, 2000, written commun.) has observed that silty sands and sandy silts typically are more susceptible to liquefaction than clean sands. It has been the experience of Obermeier (co-author), however, that dikes and liquefaction-induced features involving silty sands (say, 20 to $30 \%$ fines or more) are only rarely observed in paleoliquefaction searches in the central and eastern U.S., even where shaking has been very strong; yet nearby, liquefaction features involving clean sand source beds are often abundant.

The reason(s) for these apparent discrepancies are not known, but may relate partly to plasticity of the fines in the different regions. Increasing plasticity of the fines appears to significantly decrease liquefaction susceptibility (Ishihara 1993). With increasing plasticity, more cohesion is imparted between the individual grains in the deposit, thus decreasing the 
tendency of a loose soil to compact during rapid shearing. Seed et al. (1983) reviewed Chinese data on liquefied soils containing clayey fines and suggested that soils having more than 15 to $20 \%$ clay are unlikely to liquefy (i.e., the "Chinese criteria"), regardless of the strength of shaking. While this percentage criterion is a good preliminary guide, we anticipate that the effect of clay content is more dependent on clay mineralogy (as quantified by plasticity index and activity) and water content than on a specific percentage. (For example, the ratio of water content to liquid limit is also one of the "Chinese criteria.") When the fines content of a deposit has significant plasticity, laboratory testing may be required to determine whether the sediment is liquefiable (Robertson and Wride, 1997; Perlea et al. 1999).

The permeability of silty sands may also influence whether or not liquefaction features develop in the field. Castro (1995) suggested that the cyclic strains experienced by silty sands are the same as those experienced by clean sands under a given level of shaking. Therefore, the magnitude of pore-water pressure increase in both soils should be similar. However, as Castro (1995) suggests, the increased fines content of silty sands typically results in lower permeability, which leads to slower reconsolidation following liquefaction (and we suspect this influence increases with increasing plasticity of the fines). Thus less water is available for flow. This causes the water layer to be thinner at the top of liquefied silty sand layer than for a liquefied clean sand. The lesser flow volume and smaller water layer are less likely to hydrofracture a fine-grained cap, and therefore liquefaction features are less likely to form from a silty sand than from a clean sand.

Fines content can also have a significant influence on the measurement of penetration resistance, with an increasing fines content generally tending to have a lower penetration resistance (Stark and Olson, 1995). This decrease in penetration resistance occurs because increasing the fines content increases the compressibility and decreases the permeability of the soil. Both of these factors cause larger penetration-induced excess pore-water pressures in silty sands than in clean sands. In turn, this results in a lower penetration resistance in a silty sand than in a clean sand at equal values of relative density and effective confining pressure. Therefore, liquefaction potential relationships (e.g., Seed et al., 1985; Stark and Olson, 1995) indicate that, other things being equal, stronger shaking is required to form liquefaction features in a silty sand having the same penetration resistance as a clean sand. This finding makes sense because in order to have the same penetration resistance, a silty sand must have a higher relative density than a clean sand, thereby making the silty sand less susceptible to liquefaction.

It should be clear from the preceding discussion that numerous factors are involved in defining the liquefaction susceptibility of sands containing more than a small amount of gravel or fines. For preliminary interpretation of paleoliquefaction searches, experience shows that an absence of dikes and other liquefaction features in a fine-grained cap above a potential source sand containing more than about $15 \%$ fines should not be interpreted to rule out the possibility of strong shaking since the deposits were laid down.

\section{Effect of Depth to Water Table}

As mentioned in a previous section, the depth to the water table has a profound effect on the liquefaction susceptibility of a sand deposit and can also have an important bearing on the 
ground failure mechanism that develops. Where the water table is more than 4 to $5 \mathrm{~m}$ deep it appears that the effects of liquefaction, especially due to hydraulic fracturing, become greatly suppressed and can be scarce even where shaking is moderate (say, about $0.2 \mathrm{~g}$ ). Still, wide lateral spreads can still develop for such levels of shaking as a result of liquefaction at greater depth. In one field example, in the Wabash Valley region of Indiana-Illinois, dikes from lateral spreading as much as $0.7 \mathrm{~m}$ wide developed from a source bed of very thick, loose sand at depth, much below the base of the cap and much below other, less liquefiable sand deposits. Yet for kilometers nearby the effects of hydraulic fracturing were nonexistent, almost certainly because the cap was above the water table at the time of the earthquake. Similarly, for a water table depth in excess of $5 \mathrm{~m}$ and strong shaking (greater than about $3 / 4 \mathrm{~g}$ ), damaging lateral spreading has been reported (Holzer et al., 1999).

It is commonly observed that dikes from lateral spreading are the only ones observed in an exposure, as illustrated in Figure 5B, even where dikes are as much as $0.3 \mathrm{~m}$ wide and the water table is within $2 \mathrm{~m}$ of the surface and above the base of the cap at the time of the earthquake. Levels of shaking for this situation probably can be as high as about $1 / 4 \mathrm{~g}$ in field settings where the source sands are fluvial in origin, medium-grained, moderately well-graded, and moderately compact.

In general, if the water table is on the order of $10 \mathrm{~m}$ or more below the ground surface, the formation of liquefaction features from any failure mechanism is highly unlikely, unless shaking is severe and the field setting is conducive to their formation.

Locating the depth to the water table at the time of the earthquake is very important in making an estimate of the strength of shaking. For clean sands, fine-grained and coarser, this depth can be estimated by observing the highest level of the base of dikes (i.e., at the base of the fine-grained cap) at widespread sites. In field situations where the water table is much lower than the base of the cap, for low to even moderate severity of liquefaction, the high permeability of these clean sands would probably allow dissipation of excess pore-water pressure along the base of the cap, thereby precluding the formation of dikes in the cap.

Long bank exposures over a large region, at least kilometers in extent, in which the contact of the fine-grained cap with underlying sand can be observed are especially valuable for the approach discussed above. Where bank exposures are limited in length or in regional extent, confidence in the interpretation of the depth of the water table is increased by measuring the relative liquefaction susceptibilities of sand at various depths, both where liquefaction occurred and did not occur. Obermeier et al. (2000) discuss how these factors were incorporated to evaluate the depth of water table in the Memphis area during the 1811-12 New Madrid earthquakes.

Field observations of weathering can also be helpful in locating the maximum depth of the water table, through time. The maximum depth of the water table is indicated by the maximum depth of oxidation in permeable, granular sediment. Oxidation to this depth is a rapid process, probably requiring only months to occur in a typical field setting. In most geochemical settings, oxidization does not reverse, even through great time. 


\section{HOW STRONG WAS THEPALEO-EARTHQ UAKE?}

Much progress has been made the past few years in the development of techniques to backcalculate the strength of shaking and magnitude of paleo-earthquakes. The techniques vary widely in their basic approaches, which allows independent assessments.

Four methods are discussed below: (1) the magnitude bound method, which uses the farthest distance of paleoliquefaction features from the tectonic source to estimate magnitude; (2) the cyclic stress method, which, by means of estimates of the lower bound peak accelerations at individual sites of liquefaction, can be used in conjunction with the regional pattern of acceleration attenuation to estimate of the actual magnitude of prehistoric earthquakes; (3) energy-based solutions, which offer the advantage of using fundamental parameters of earthquake strength and susceptibility to liquefaction, and (4) the Ishihara method, which uses dike height at a site of hydraulic fracturing to estimate the peak acceleration at the site. The first two methods lie within the class of conventional, well-known procedures that are applicable for many field and tectonic settings. The latter two are still in development, but can be useful in their present status to verify paleoseismic interpretations. Selection of the appropriate method(s) depends on the data available at the field sites, as shown in examples below.

In this section we use the first two techniques above to determine the prehistoric levels of shaking in a single study area, the Wabash Valley region of Indiana-Illinois. For comparison, we also use an energy-based solution, the energy-stress method of Pond (1996). The Wabash Valley region lies in an area of intraplate seismicity in which the largest historical earthquake (during the past 200 years) has been M 5.8. Paleoliquefaction features clearly demonstrate, however, that numerous and much larger Holocene earthquakes have been centered in the region on the basis of sizes of liquefaction features and the regional extent of liquefaction from these earthquakes. This region is typical of many where paleoliquefaction interpretations are especially useful, i.e., there are no surface faults available for study and the prehistoric earthquakes are spaced widely enough in time to separate their liquefaction effects from one another.

Evaluation of the prehistoric levels of shaking in the Wabash Valley presents challenges, however, because of the absence of seismological measurements for large earthquakes in the region. Seismological measurements are available only for small earthquakes $(\mathbf{M}<5)$. The behavior of these smaller earthquakes has been extrapolated to predict the behavior of much larger events for some of the analyses we discuss in this section, but such an extrapolation may not reflect reality. Such uncertainty exists in most regions where paleoliquefaction studies have been much used as the basis for interpreting the prehistoric record (i.e., the central and eastern U.S.). Unknown seismic factors in the Wabash Valley region include the stress drop, which can have a large effect on the strength of shaking (Hanks and Johnston, 1992) and possibly other factors, such as strength of shaking at various frequencies, in which some frequencies may be too high to induce shear strains large enough to cause liquefaction. Another factor, a deep focal depth, can cause the strength of shaking to be diminished at the ground surface, above the focus. And, unlithified sediment of considerable thickness (hundreds to thousands of meters) above bedrock may alter the severity and/or frequency content of shaking as it is transmitted up from the bedrock. 
A preferred orientation of strong shaking (i.e., directionality) can also complicate interpretations of prehistoric strength of shaking. For strike-slip faulting, the effects of directionality can be manifested as higher accelerations along the projection of the fault axis. Other types of faulting have other types of directionality effects. However, a paleoliquefaction search that encompasses a large region should clarify effects of directionality, permitting proper use of the procedures for back-analysis of strength of shaking and magnitude. These procedures for back-calculations are based on techniques that provide only maximum levels of shaking as a function of earthquake magnitude and distance from the energy center, regardless of orientation from the energy center;

this requires, therefore, that back-calculations for paleoseismic interpretations determine the highest level of (bedrock) shaking as a function of distance from the energy center.

The confidence in interpretations of prehistoric levels of shaking is highest where different procedures for back-calculation yield the same results. Even in this case though, there can be some uncertainty because some of the methods may depend similarly on the assumed seismic parameters such as stress drop and focal depth.

The paleo-earthquakes in the Wabash Valley region that are the subjects for our case history examples are shown in Figure 9. The figure shows the areal extent of dikes caused by paleoearthquakes centered in the region. Figure 9 also shows the maximum dike width located at individual sites along a stream bank. The areal limit of liquefaction-induced dikes is indicated for various paleo-earthquakes, as are their ages. The ellipsoidal-shaped pattern of liquefaction features for each of the paleo-earthquakes in Figure 9 indicates significant directionality, and the techniques for back-calculations complied with this pattern as explained below. Evaluations of prehistoric magnitudes for four large paleo-earthquakes in the Wabash Valley region are given in Table 3.

The effects of directionality were accounted for in the back-analysis methods listed in Table 3 by using the level of shaking along the long axes of liquefaction effects. The back-calculation procedures and the estimates of magnitudes are discussed in the following section.

Table 3. Back-calculated magnitudes, $M$, for the four largest paleo-earthquakes centered in the Wabash Valley region of Indiana. Earthquake ages (Munson and Munson, 1996) are in parentheses, and are given in radiocarbon years or approximate timing.

\begin{tabular}{ccccc}
\hline & \multicolumn{4}{c}{ Paleo-earthquake } \\
\cline { 2 - 5 } Back-Analysis & Vincennes & Skelton & Vallonia & Waverly \\
\cline { 2 - 5 } Method & $\mathbf{( 6 , 1 0 0 )}$ & $\mathbf{( 1 2 , 0 0 0 )}$ & $\mathbf{( 3 , 9 5 0 )}$ & $\begin{array}{c}\text { (mid- } \\
\text { Holocene) }\end{array}$ \\
\hline Magnitude bound & 7.8 & 7.2 & 6.9 & 6.8 \\
\hline Cyclic stress & $7.5-7.7$ & 7.4 & 6.7 & 6.9 \\
\hline Energy-stress & $7.5-7.8$ & 7.3 & 7.1 & $6.8-7.1$ \\
\hline
\end{tabular}




\section{Magnitude Bound Method}

The magnitude bound method estimates the magnitude of a paleo-earthquake by using relations between earthquake magnitude and the distance from the tectonic source to the farthest site of liquefaction. The method is based on increasingly stronger earthquakes causing liquefaction at increasing distances from the energy center, in a systematic manner. Data affecting the extent of liquefaction are preferably available from historical earthquakes in a study area, to account for the influence of local factors such as stress drop, focal depth, and liquefaction susceptibility.

Figure 10A shows the distance from the epicenter to the farthest liquefaction feature for many worldwide, historical earthquakes (Ambraseys, 1988). Also shown is a limiting bound for this relationship, as proposed by Ambraseys (1988). Almost all data points in Figure 10 are from sites of minor venting of sand or minor lateral spreading. (Sites having only soft-sediment deformations, such as ball-and-pillows, load casts, or convoluted bedding, were not included in the data set.) The data are from various tectonic conditions and susceptibilities to liquefaction, and so it is not surprising that the maximum extent of liquefaction is highly variable for a given earthquake magnitude. The bound represents optimal conditions for the formation of liquefaction features, considering all factors.

Figure 10A also has a single data point from Tuttle et al. (1992). The reason that point extends considerably beyond the bound of Ambraseys (1988) is unknown, but may be the result of an exceptional field effort to locate the farthest extent of liquefaction. Or, the anomalous point may be the result of an exceptionally deep focus $(29 \mathrm{~km})$ or large stress drop for the Saguenay earthquake. Data from Ambraseys (1988) clearly show that an increase in focal depth tends to cause an increase in the farthest extent of liquefaction.

A problem with using a bound such as shown in Figure 10A for paleoseismic analysis of highermagnitude earthquakes is illustrated in Figure 10B, where it is seen that the epicenter is often far removed from the energy center (e.g, Bartlett and Youd, 1992). Where both the energy source and the outer limits of liquefaction of a paleo-earthquake are well defined, however, a reasonable estimate of prehistoric magnitude can be achieved in many study areas, at least in terms of destructive potential, as illustrated in the following example.

Figures $10 \mathrm{~A}$ and $10 \mathrm{~B}$ also show the limiting bound from the energy center for the Wabash Valley region of Indiana-Illinois (Fig 7), which was developed by Obermeier et al. (1993) and Pond (1996) using liquefaction effects from three historical earthquakes (of $\mathbf{M}$ 8.1, 6.8, and 5.6) in the nearby New Madrid seismic region, which was presumed to have similar seismic characteristics to that of the Wabash Valley region. We note that the largest historical earthquake in the New Madrid region, from the 1811-12 series, is now thought to have probably been of M 8.0-8.1 (E.S Schweig, U.S. Geological Survey, 1999, oral commun.), as shown in Figure 10, rather than the value of M 8.3 that was used to originally develop the curves in Figure 10. The difference in magnitude is insignificant in the following interpretations for paleomagnitudes in the Wabash Valley region. Two segments of the bound are shown in Figure 10B, one for earthquakes stronger 


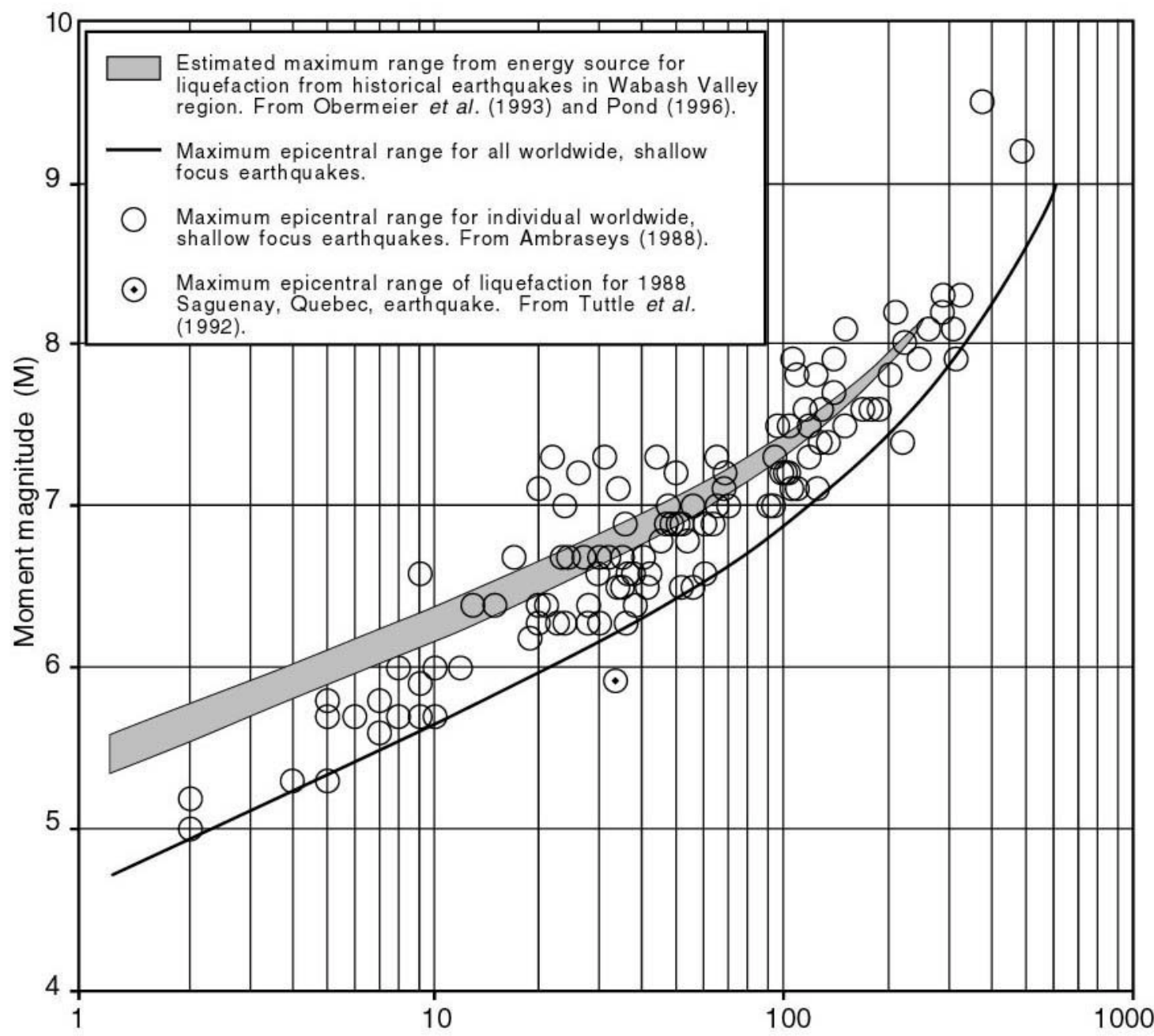

Maximum distance to surface evidence of liquefaction-induced ground failure $(\mathrm{km})$

Figure 10. A. Moment magnitude versus maximum distance from epicenter to farthest surface evidence of liquefaction effects, for shallow-focus $(<50 \mathrm{~km})$ earthquakes. B. Moment magnitude versus maximum distance from energy center to farthest surface evidence of liquefaction effects for shallow focus $(<50 \mathrm{~km})$ earthquakes worldwide (Ambraseys, 1988) and for the Wabash Valley region. Also shown is the bound from Figure 10A for epicentral distance. 
than $\mathbf{M} 6.8$ and the other for smaller earthquakes. The portion of the bound for $\mathbf{M}>6.8$ earthquakes was used to estimate the magnitude of the larger $(\mathrm{M} \sim 6.9$ to 7.8$)$ prehistoric earthquakes of the Wabash Valley region (Munson and Munson, 1996; Pond, 1996; Obermeier et al., 1993; Obermeier, 1998a).

The portion of the bound for $\mathbf{M}>6.8$ earthquakes that we used for analysis of Wabash Valley earthquakes lies relatively close to that of Ambraseys (1988). For $\mathbf{M} \sim 7.5$ and higher earthquakes the bound used for the Wabash Valley exceeds that of Ambraseys, but for $\mathbf{M}<7.5$ it is less than Ambraseys'. The bound for the Wabash Valley is suspected to differ from Ambraseys (1988) because of two factors: (1) the low attenuation of bedrock shaking in the central U.S.; and (2) with decreasing magnitude, there is a diminishing availability of sites having very high susceptibility to liquefaction. These two effects are increasingly opposing to one another with decreasing magnitude. The extraordinarily lowattenuation of shaking from very large earthquakes in the central U.S. was exemplified by the abnormally large area of strong shaking from the great New Madrid earthquakes of 1811-12 (e.g, Nuttli, 1973); but, as is well known among seismologists, the influence of bedrock attenuation on the regional extent of strong shaking diminishes with decreasing earthquake magnitude. In contrast, the probability of sites having high liquefaction susceptibility decreases with decreasing magnitude, on average, because of the decreasing likelihood of strong shaking occurring in areas having sand deposits that are very young and thick, and thereby having very high liquefaction susceptibility. This reduced probability was likely important in defining the lowermost portion of the bound for the Wabash Valley in Figure 10, where occurrence of liquefaction from a single historical $\mathbf{M} \sim 5.6$ earthquake (Metzger, 1996) was used to help define that portion (Pond, 1996). The $\mathbf{M} \sim 5.6$ earthquake may have struck in an area less than optimal for development of liquefaction features (i.e., the earthquake struck in an area having no large stream valleys nearby with very young deposits). If the $\mathbf{M} \sim 5.6$ earthquake had struck near a major river, we suspect the extent of liquefaction might have been nearer the bound by Ambraseys (1988). Thus, when using the magnitude-distance boundary developed for the Wabash Valley region in Figure 10B for interpretation of paleomagnitude, it is important to consider the field setting of the earthquake.

For lower-magnitude earthquakes $(\mathbf{M}<\sim 7)$, we suspect that the bound for even the most optimal conditions for liquefaction in the Wabash Valley does not extend as far as that of Ambraseys (see Fig. 10B), because the liquefaction susceptibility of the youngest deposits in the Wabash Valley region is, in general, probably not as high as that of young sediments in some other geologic settings. The granular sediments in the Wabash Valley region, laid down in Holocene time, are typically fairly well-graded clean sands; such well-graded sands likely have significantly lower liquefaction susceptibility than, for example, uniformly-sized sands (T suchida, 1970).

Case history examples and field verification. The following two examples illustrate the application of the magnitude bound method to the larger paleo-earthquakes in the Wabash Valley region, all of whose regional patterns of liquefaction features were reasonably well defined (Fig 9). (Such good definition generally does not occur for the smaller paleo-earthquakes, as discussed previously.) For the Vincennes earthquake of $6,100 \mathrm{yr}$ BP, the energy center was near the town of Vincennes (Fig 9). The liquefaction feature farthest from the energy center was found in the bank of the Wabash River, about $165-170 \mathrm{~km}$ to the north-northeast (Fig 9). Using this distance with the Wabash valley region bound in Figure 10B yields $\mathbf{M} \sim 7.8$. 
For the Vallonia earthquake of 3,950 yr BP (located in the southeastern Indiana, Fig. 9), the farthest distance of liquefaction from the energy center (about $45 \mathrm{~km}$ ) was taken as the farthest distance from the largest dikes, even though these dikes were located a considerable distance from the center of the discovered liquefaction features. This large skewing of the energy center is likely due to the poor bank exposures along the river west of the largest dikes. Using the distance of 45 $\mathrm{km}$ from the presumed energy center, the magnitude bound solution for the Wabash Valley in Figure 10B yielded $\mathbf{M} \sim 6.9$.

We note again that for both of these paleo-earthquakes as well as the two other largest, the magnitude bound method yielded the same magnitude as the cyclic stress method (Table 3 ). The magnitude bound method appears to have worked well for the larger paleo-earthquakes in the Wabash Valley because written accounts of historical liquefaction were adequate to develop the bound in Figure 10. The bound for the larger earthquakes was defined chiefly by data from two historical earthquakes of $\mathbf{M} \sim 6.8$ and 8.1 (see Obermeier et al., 1993, for details). Use of data for M 8.1 (of the 1811-12 New Madrid series of earthquakes ) is illustrative. The data points for $\mathbf{M} 8.1$ (not shown in Figure 10) represent sites where liquefaction effects were widely scattered yet still noticed by people living throughout the area of Indiana-Illinois. The liquefaction features that they observed formed in field settings probably most highly susceptible to liquefaction (relatively young sediments probably less than a few thousand years in age, consisting of very thick sands veneered with a thin fine-grained cap, in local settings where surface motions likely were amplified from bedrock shaking). Therefore, the written accounts most likely approximate the distance where the most distal liquefaction features developed - and also approximate the distance that liquefaction features from a prehistoric earthquake can be relocated in a paleoliquefaction search. This equivalence of distances appears to have been confirmed by the results of extensive searching for liquefaction features caused by the 1811-12 earthquakes. Searches were conducted far beyond the epicentral region of the 1811-12 earthquakes to the northeast (in the vicinity of the Ohio and Wabash Valleys) as well as to the northwest (especially along the Kaskaskia River in the vicinity of the Mississippi Valley, near St. Louis, Missouri; Fig. 7). The paleoliquefaction searches both to the northeast and to the northwest discovered only scattered, small dikes that could have been caused by the 1811-12 earthquakes, and these dikes were present in the vicinity of the most distal, historically observed liquefaction features from the 1811-12 New Madrid earthquakes (Obermeier, 1998a; McNulty and Obermeier, 1999). No young dikes were found beyond the limits of the historical observations in 1811-12.

We suspect that two factors explain why the young dikes found in the paleoliquefaction search were discovered in the same distal locales as those of the historical observations for the 1811-12 New Madrid earthquakes: (1) a great length of river banks was searched throughout a large region in the vicinity of the historical observations (see Fig. 7); and (2) the searched areas were in field settings (along rivers) where the most distal liquefaction features typically develop. It was noted in a previous section that lateral spreads typically develop farthest from the meizoseismal zone, and that lateral spreads very commonly develop near river banks. It was also noted previously that dikes from lateral spreading typically develop considerably back from the river banks, tens to hundreds of meters, even where lateral spreading is not severe (see Fig. 5). Erosion of the river 
banks exposes these dikes hundreds to thousands of years after they formed in many field situations.

In South Carolina it was similarly found that the farthest historical observations of liquefaction features agreed well with the results of a paleoliquefaction search. A $\mathbf{M} \sim 7.3$ earthquake struck near Charleston in 1886 (Johnston, 1996). Newspaper accounts reported liquefaction-types of ground failure as far as $100 \mathrm{~km}$ south of Charleston. Searches one hundred years later located only scattered, small liquefaction features, as far as $100 \mathrm{~km}$ south of Charleston, which could be associated with the earthquake of 1886 (Obermeier et al., 1993, p. 21-22). No features were found beyond this distance despite extensive field searching.

In summary, the two paleoliquefaction searches discussed above had findings that agreed well with the historical observations of most distal liquefaction effects. Both regions searched for paleoliquefaction features had extensive exposures, and, as a result, have probably provided realistic calibrations for the magnitude bound method.

The magnitude bound method has been used in a more qualitative manner to estimate the magnitudes of prehistoric earthquakes in South Carolina and the New Madrid seismic zone. Historical observations of liquefaction effects have also been used in coastal South Carolina (Obermeier, 1993, 1996a) to show that prehistoric earthquakes were probably at least as strong as the $\mathbf{M} \sim 7.3$ earthquake near Charleston in 1886, because of the following: (1) the limits of liquefaction from the prehistoric earthquakes extended at least as far from Charleston as those formed during the 1886 earthquake of $\mathbf{M} \sim 7.3$, even at precisely the same field sites of liquefaction, and (2) the liquefaction susceptibility of the deposits subjected to the prehistoric earthquakes was almost certainly as high as for those subjected to the earthquake of 1886 . More recently, Tuttle (1999) used a similar approach to show that some of the largest prehistoric earthquakes in the New Madrid seismic zone probably were about as strong as the largest $(\mathbf{M} \sim 8.1)$ of the 1811-12 series.

Water Table Depth. Confidence in the interpretation of paleomagnitude using the magnitude bound method also requires knowledge of the approximate depth of the water table at the time of the earthquake. The magnitude bound method probably has worked well for the larger paleoearthquakes in the Wabash Valley region because field settings with relatively high water tables have been maintained, through time, within the area encompassed by strong shaking from the larger earthquakes $(\mathbf{M}>\sim 7)$. Many streams in the region are very underfit in that they occupy valleys that formed when great quantities of sediment were debouched during melting of the glaciers. These valleys can be kilometers wide and at many places contain tens of meters of sand and gravel capped by a thin silt layer. Radiocarbon data, in conjunction with observations of depth of weathering in sands beneath the fine-grained cap, show that the depth to the water table in many of these valleys has rarely been greater than 2 to $3 \mathrm{~m}$ throughout the Holocene (Obermeier, 1998a). Thus, liquefaction susceptibility has remained relatively constant through Holocene time, excluding the effects of aging, which we noted in a previous section (Liquefaction Susceptibility) were probably minor in this region.

The valleys with underfit streams are so common throughout the Wabash Valley region that strong shaking from a $\mathbf{M}>7$ earthquake would likely have caused liquefaction in some of these 
deposits. However, as magnitude decreases, the likelihood of encountering such valleys diminishes greatly, thereby increasing the uncertainty in interpretations for these lower-magnitude earthquakes.

\section{Cyclic Stress Method}

Seed et al. (1985) updated a procedure originally proposed by Seed and Idriss (1971) to evaluate the liquefaction potential of sandy soils. The procedure is based on case histories of sites that did or did not develop liquefaction effects during earthquakes worldwide. The occurrence of liquefaction was judged from many types of observations, such as sand blows caused by hydraulic fracturing, lateral spreading, ground cracking or settlement, and damage to structures caused by settlement or tilting.

The Seed et al. (1985) method and its predecessors were originally developed as a geotechnical procedure to estimate the strength of cohesionless sediment required to prevent liquefaction during an earthquake, for a given earthquake magnitude and peak acceleration. The method is based on comparing the earthquake-induced (horizontal) cyclic shear stress to the cyclic resistance of the soil (i.e., to the strength of the soil or its resistance to pore-water pressure buildup). The earthquake-induced cyclic shear stress is related to both the strength and duration of shaking. These values, in turn, statistically relate to earthquake magnitude. The influence of the seismically-induced horizontal shear stress is incorporated within the parameter of cyclic stress ratio (CSR); CSR is a function of earthquake magnitude, peak surface acceleration, the total and effective overburden stresses, and the depth of the source bed. The strength of the soil is evaluated in terms of the parameter $\left(\mathrm{N}_{1}\right)_{60}$, which is the SPT blow count value (N) normalized to account for depth of sediment and the water table, as well as for the specific type of SPT test equipment.

Figure 11A shows the boundary relationship proposed by Seed et al. (1985) (and later modified by Youd and Noble, 1997) delineating conditions where liquefaction is likely from where it is unlikely. The bound was developed for $\mathbf{M} \sim 7.5$. For a given $\left(\mathrm{N}_{1}\right)_{60}$ value, earthquake-induced shear stresses (i.e., CSR values) that plot above the boundary relationship have a high potential to cause the formation of liquefaction features. Figure 11A also shows the "simplified" equation that can be used to approximate the cyclic stress ratio (CSR). Seed et al. (1983) developed factors to scale the M 7.5 base curve of Figure 11A to magnitudes other than 7.5. Figure 11B presents the effect of the "magnitude scaling factor" (MSF) on the $\mathbf{M} 7.5$ base curve. Youd and Idriss (1997) updated the magnitude scaling factors, which now show greater uncertainty for earthquakes larger or smaller than M 7.5. Also, as illustrated by comparing the boundary relationships for $\mathbf{M} 7.5$ in Figures $11 \mathrm{~A}$ and 11B, higher values of $\left(\mathrm{N}_{1}\right)_{60}$ (greater than 25) are considered to be less susceptible to liquefaction than was thought in 1983.

To account for site-specific conditions and reduce the uncertainty involved in using the "simplified" equation for cyclic stress ratio, a site response computer program can be used to estimate seismic shear stresses. One-dimensional equivalent linear site response programs (such as SHAKE91, Idriss and Sun, 1992) are used routinely in practice to obtain reasonable estimates of free-field accelerations, stresses, and strains in many field settings. The maximum seismic shear stresses determined by an equivalent linear site response program can be 


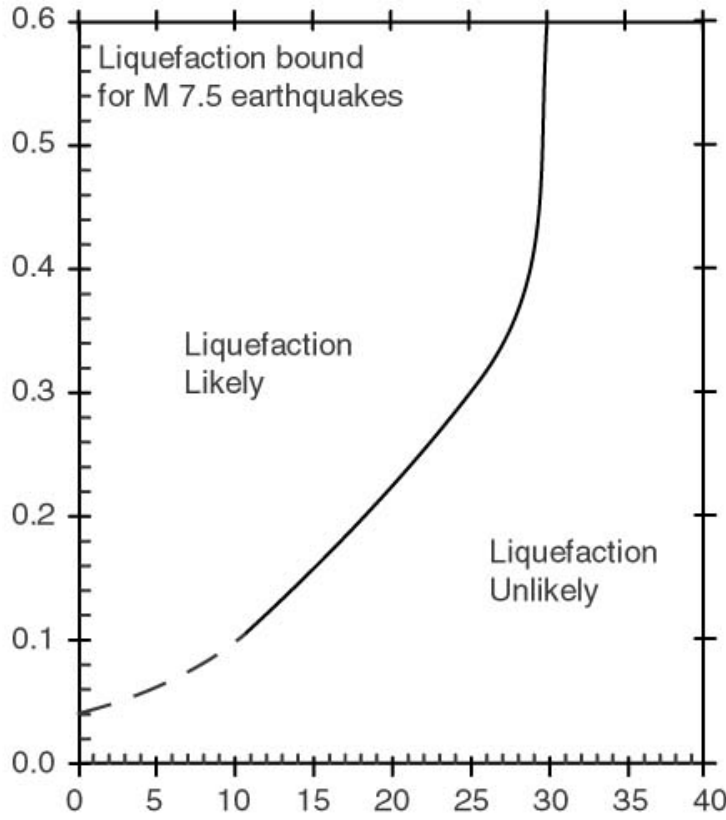

Corrected Standard Penetration Test value, $\left(\mathrm{N}_{1}\right)_{60}$ $\tau_{\mathrm{h}}$ average Average earthquake-induced horizontal cyclic shear stress.

$\sigma_{0}^{\prime} \quad$ Initial vertical effective overburden stress.

$\left(\mathrm{N}_{1}\right)_{60} \quad$ Standard Penetration Test blow count measured in field, modified to blow count resistance at vertical effective stress of 1 ton $/ \mathrm{ft}^{2}(97.5 \mathrm{k} \mathrm{Pa})$ and 60 percent of the theoretical free-fall energy.

Peak acceleration, $a_{\max }$, is given by the following relationship in Seed et al. (1985):

$$
\text { Cyclic Stress Ratio }=0.65 \cdot \frac{a_{\max }}{g} \cdot \frac{\sigma_{\circ}}{\sigma_{\circ}^{\prime}} \cdot r_{d}
$$

where $\sigma_{0}=$ total overburden stress at the depth of interest, $\sigma_{\circ}^{\prime}$ is the initial vertical effective stress there, $\mathrm{g}$ is the acceleration due to gravity, and $r_{d}$ is a stress reduction factor decreasing from 1 at the ground surface to 0.9 at the depth of $10 \mathrm{~m}$.

Figure 11. (A) Seed et al. (1995) method showing curve for evaluation of the potential occurrence of liquefaction with accompanying venting of sand or appreciable ground cracks for sites on level ground and a M 7.5 earthquake. Curve is for clean sand deposits. Points above and to the left of the curve have a high potential for liquefaction. Modified from Youd and Noble (1997). 


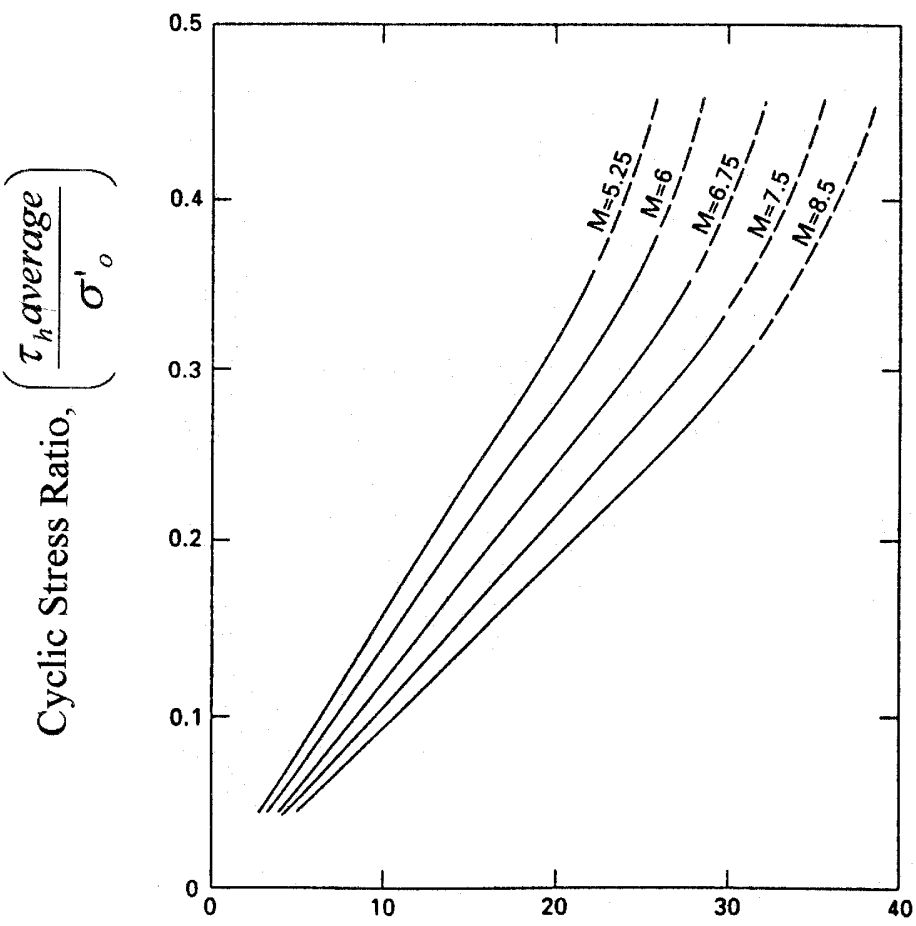

Normalized Standard Penetration Test value, $\left(\mathrm{N}_{1}\right)_{60}$

Figure 11. (B) Seed et al. (1983) curves for various values of earthquake magnitude, $M_{I}$, or surface wave magnitude, $M_{S}$, whichever is larger. The curves differ very little for the same value moment magnitude, M. (Relations between the different magnitudes are given in pages 495-497 of McCalpin (1996).) 
converted into equivalent uniform cyclic shear stress ratios at all depths as follows:

$$
C S R=\frac{\tau_{h}(\text { ave })}{\sigma_{v o}^{\prime}} \cong 0.65 \frac{\tau_{\max }}{\sigma_{v o}^{\prime}}
$$

where $\tau_{\mathrm{h}}$ (ave) is the equivalent uniform cyclic shear stress and $\tau_{\max }$ is the maximum seismic shear stress output by the program. The cyclic stress ratio determined above can be used in conjunction with liquefaction potential relationships (such as that shown in Figure 11A) to evaluate the triggering of liquefaction at free-field, level ground sites. When CSR is determined using a site response program, the depth reduction factor is not required because it is explicitly accounted for by using the values of maximum shear stress with depth output by the program. The magnitude scaling factor must still be used though, because the liquefaction potential relationships are based on an approximate $\mathbf{M} 7.5$ earthquake.

It should be recognized that equivalent linear one-dimensional site response programs may provide unreliable results for some seismic and site conditions. The conditions include: (1) when bedrock accelerations exceed about $0.4 \mathrm{~g}$ (or whenever the non-linear behavior becomes important); (2) when soft soils are present in the soil column; or (3) where the soil column is deep (say, possibly more than $30 \mathrm{~m}$ ). The first two conditions apply to the interpretation of accelerations, stresses, and strains, because the stress-strain behavior of soil can become highly non-linear with higher base accelerations. Therefore, judgment must be used to select values of shear stresses to be used in liquefaction analysis, especially when accelerations exceed about 0.4 g. Soft layers below potentially liquefiable layers can develop large shear strains during seismic shaking and act to isolate potentially liquefiable layers farther up the soil column. However, equivalent linear site response programs do not model soil behavior at large strains very well, and therefore must be used with caution when this field setting is encountered. A detailed discussion of the seismic analysis of sites with soft layers underlying potentially liquefiable layers is beyond the scope of this paper. The third condition of deep soil columns involves deficiencies of all current site response codes (one- and two-dimensional, equivalent linear and non-linear) to properly model the modulus degradation and damping behavior of soils under high confining pressures. Preliminary research (Hashash and Park, in press) indicates that ignoring this behavior can result in significant attenuation of bedrock motion. Their analyses show considerably higher values of acceleration, shear stress, and shear strain propagated through the soil column.

In addition, equivalent linear site response programs cannot account for an increase in porewater pressure (and concurrent degradation of shear modulus) that can occur during shaking in a liquefiable deposit. Therefore, these programs should not be used for independent evaluation of pore-water pressure increase and liquefaction potential. However, as discussed above, these programs can be used with relative confidence in many field settings to conduct "total stress" analyses and evaluate seismic shear stresses to be used in conjunction with liquefaction potential relationships, such as that shown in Figure 11A.

Figure 12 shows the updated version of Figure 11A presented by Youd and Noble (1997), who used a much larger data base than Seed et al. (1985) to develop liquefaction resistance relations in terms of the logistic probability of liquefaction, $\mathrm{P}_{\mathrm{L}}$. (A logistic probability of $50 \%$ means there is 


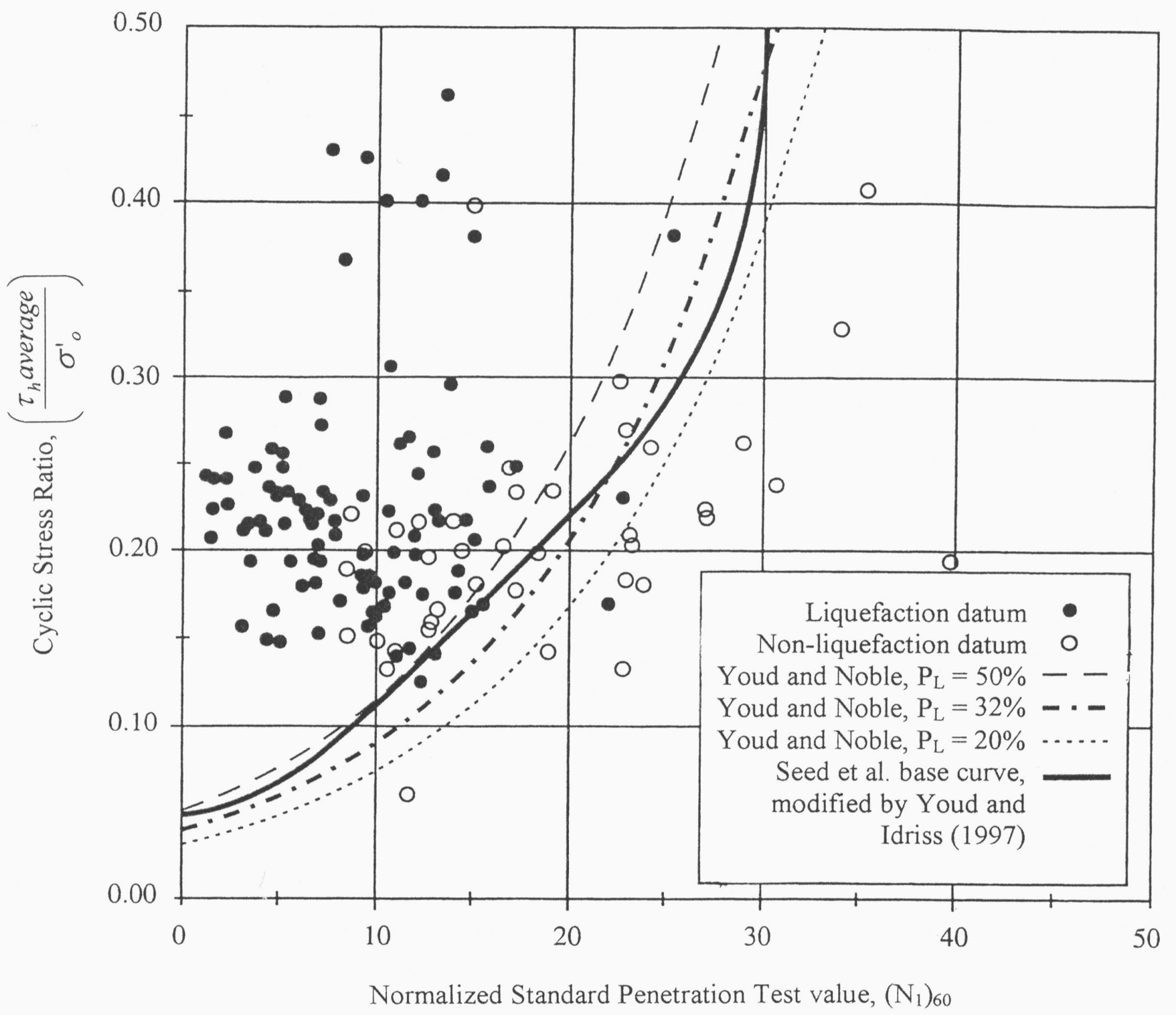

Figure 12. Probabilistic liquefaction resistance curves for $\mathrm{P}_{\mathrm{L}}$ of $50 \%, 32 \%$, and $20 \%$, and for $\mathbf{M}$ $7.5 \pm 0.25$ (Youd and Noble, 1997). Seed et al. (1985) clean sand base curve, as modified by Youd and Idriss (1997), is also shown. 
an equal likelihood of liquefaction occurring or not occurring, and the curve for a probability of $50 \%$ most likely represents marginal development of liquefaction effects.) Figure 12 illustrates that even for the expanded data base there are insufficient data at higher values of CSR (i.e., for higher levels of shaking, or greater depths of sediment or deeper water tables) and also at higher values of $\left(\mathrm{N}_{1}\right)_{60}$ (values greater than 20) to have much confidence in the interpretations.

The liquefaction resistance relationships shown in Figures 11A and 12 are based on SPT data that were measured soon after the occurrence of the causative earthquakes. In most cases, blow counts were measured shortly after the earthquake, but likely after the dissipation of excess pore-water pressure and resulting densification of the source bed(s). Therefore, post-earthquake aging is expected to be negligible for most of the cases in the SPT data base (Olson et al., 2001). No "corrections" to the measured blow counts were made to account for pre-earthquake aging, densification of strata, or any other such effects in developing the liquefaction resistance relations shown in Figures 11A and 12.

The data in Figure 12 incorporate all mechanisms of liquefaction-induced ground failure (hydraulic fracturing, lateral spreading, surface oscillations) and no distinction is made among these mechanisms. For other than exceptionally strong earthquakes with very strong shaking, though, the boundary likely represents the threshold for lateral spreads, at least for $\left(\mathrm{N}_{1}\right)_{60}$ values up to about 15 to 20. The failure mechanism can differ at higher values of $\left(\mathrm{N}_{1}\right)_{60}$ because liquefied ground becomes increasingly stiff under applied unidirectional strain as $\left(\mathrm{N}_{1}\right)_{60}$ increases. This increased stiffness makes lateral spreading more difficult and less probable in comparison to other mechanisms of ground failure (Seed et al., 1985, p. 1440-1441; Bartlett and Youd, 1992).

To reiterate, at low to moderate $\left(\mathrm{N}_{1}\right)_{60}$ values (say, less than about 10 to 15), the Seed et al. (1985) bound approximates conditions for the threshold development of lateral spreading. At these values of $\left(\mathrm{N}_{1}\right)_{60}$, though, the boundary relationship also probably closely approximates the threshold for marginal development of ground failure from other mechanisms, in many field settings. This overlap of mechanisms is realized because at low to moderate $\left(\mathrm{N}_{1}\right)_{60}$ values, granular sediment is generally contractive or collapsible (e.g., Fig. 8 in Seed et al., 1985; Castro 1987) and thus liquefaction occurs readily under low to moderate levels of earthquake shaking. When granular sediment is this loose, lateral spreading of level ground most likely occurs on sediment that is liquefied completely (or nearly so), where the pore-water pressure approximately equals the total overburden pressure of the overlying sediment. However, if liquefaction occurs, the pore-water pressure is likely to be large enough to hydrofracture a thin cap (say, about $1 \mathrm{~m}$ thick). Therefore, for these low $\left(\mathrm{N}_{1}\right)_{60}$ values, the Seed et al. (1985) boundary relationship is probably synonymous for either lateral spreading or hydraulic fracturing through a thin fine-grained cap.

As noted previously, at higher values of $\left(\mathrm{N}_{1}\right)_{60}$ lateral ground displacements are much more restricted, and "sand boils" (i.e., hydraulic fracturing) can be the mechanism of ground failure that is most manifest (Seed et al., 1985). Still, at least some significant breakage of the cap probably develops at values of $\left(\mathrm{N}_{1}\right)_{60}$ higher than 15 to 20 due to the initial tendency for lateral spreads to develop prior to soil dilation (e.g, see Fig. 8 in Seed et al., 1985). As a consequence, we suspect that throughout the range of $\left(\mathrm{N}_{1}\right)_{60}$ values, the threshold cyclic stress ratio (and thus acceleration) 
is nearly the same for the various mechanisms of liquefaction-induced ground failure, at least for the situation of a thin cap and a large to very large earthquake.

Application to paleoliquefaction studies. The liquefaction resistance boundaries in Figure 12 were developed almost exclusively from field observations at the surface (plan view) after the earthquakes. The data used to develop the boundaries do not explicitly consider the influence of cap thickness on liquefaction-induced ground failure, which can have a very significant effect on whether dikes penetrate completely or only partially to the surface. Thus, by using ground surface observations, sites of liquefaction where dikes have penetrated only partially to the surface have doubtlessly been missed at many places in development of Figure 12. Inclusion of all dikes may cause the liquefaction resistance curves based on $\mathrm{P}_{\mathrm{L}}$ to be shifted to the right (i.e., to higher values). However, because sites of liquefaction used to develop Figure 12 also were identified by settlement and damage to buildings, and not just venting and ground failure, this discrepancy may be reduced. Furthermore, in some field settings, e.g., unrestrained face and a mild slope, minor lateral spreading may be possible under conditions of increased pore-water pressure (and thus decreased shear resistance) without liquefaction occurring. This would also tend to reduce the possible discrepancy between plan view and sectional view observations.

The development of the liquefaction resistance boundaries using plan view observations is justified to predict the future occurrence of liquefaction, because this observational view also implies a certain level of severity of liquefaction and thereby damage potential - and it is damage potential that is most relevant for engineering design. The development of boundaries from plan view observations can complicate paleoliquefaction interpretations, however. Paleoliquefaction searches are generally conducted in vertical (sectional) view, in which small dikes (say, less than a meter in height) are commonly observed to penetrate only a small fraction of the height of the fine-grained cap, especially at sites where the cap is thick (see Fig. 1B). For such a site, using the bound for $\mathrm{P}_{\mathrm{L}}$ equal to $50 \%$ (Fig 12, which we anticipate to correspond to marginal liquefaction in plan view) to back-calculate the strength of shaking would likely result in a value that is too high, and possibly much too high.

Another factor that is relevant in many paleoliquefaction studies is selection of the source bed where liquefaction initiated. This can be difficult where thin, loose strata occur within other strata that are more resistant to liquefaction. Such is commonly the case directly below a fine-grained cap, where a layer of loose sand, a fewto several tens of centimeters in thickness, is underlain by thick sand that is more compact and resistant to liquefaction. The question can arise of whether liquefaction of the thin, loose stratum would have sufficed to develop any observed dikes, particularly in settings where lateral spreading is unlikely.

Some guidance to this question is provided by recent studies utilizing CPT measurements, which permits much better resolution of in-situ stratigraphy than the SPT method. Compilations of CPT data from many earthquakes (Stark and Olson, 1995) indicate that surface liquefaction effects typically develop where the loose or liquefiable sediment has a minimum thickness of about 0.5 to $1 \mathrm{~m}$ and the cap thickness ranges from about 2 to $6 \mathrm{~m}$ (S.M. Olson, co-author). Stark and Olson (1995) used a minimum layer interval of $0.3 \mathrm{~m}$ to determine the average tip resistance. The bound shown by Stark and Olson (1995) separating field occurrences of liquefaction and no liquefaction is very sharp, even for higher values of CPT tip resistance, although only limited data 
were available for the higher values. In a later study of a single earthquake (Loma Prieta), Boulanger et al. (1997) concluded that a minimum thickness interval of $0.2 \mathrm{~m}$ should be used to determine average CPT tip resistance; but, they also concluded that the predicted liquefaction resistance differed little whether thickness intervals of 0.1 or $0.3 \mathrm{~m}$ were used to average the CPT tip resistance.

In a related study, Gilstrap (1998) examined a large CPT data base and found that CPT based liquefaction resistance curves (similar to the SPT based relationships shown in Figure 12) correctly delineated where liquefaction would occur with an accuracy of $89 \%$ and would not occur with an accuracy of $86 \%$. Gilstrap (1998) eliminated cases where very thin zones of potentially liquefiable sand were overlain by a cap that was obviously much too thick to be penetrated to the surface by hydraulic fracturing.

An important factor regarding the location and thickness of the critical zone for back-analysis is that an occurrence of liquefaction commonly leaves a thin zone of loose sand located directly beneath the cap; using this zone for back-analysis can lead to an underestimate of the level of shaking. In the New Madrid region, this zone is as much as $0.7 \mathrm{~m}$ thick where liquefaction was severe during the 1811-12 earthquakes (Obermeier, 1989, 1996a). Such a thickness likely represents an upper limit at nearly all sites of liquefaction from earthquakes worldwide, because of the severity of liquefaction in the New Madrid region (where venting left as much as a meter of sand on the surface at many places).

Paleoliquefaction sites that are appropriate for estimating actual strengths of shaking using relations in Figure 12 are limited. Back-calculation at a site of severe liquefaction may reflect only a lower bound of shaking, and this lower bound can be much too low. Even sites of marginal liquefaction, for which the curve for $\mathrm{P}_{\mathrm{L}}$ of $50 \%$ generally applies, can cause problems in backcalculating accelerations. Only the loosest sediment can confidently be assumed to have liquefied. As a result, at a given site, the relations in Figure 12 can yield only a lower bound of prehistoric accelerations and magnitudes in many field situations. This problem can be circumvented, however, by using many sites of liquefaction throughout a large region, as will be illustrated in the case history example in the following section.

The relations in Figure 12 can be particularly useful for paleoseismic analysis in regions where there are no liquefaction features. For this situation an upper bound acceleration can be estimated by assuming that, somewhere, the loosest source beds should have liquefied and produced very small dikes. A regional approach is required in order to have much confidence in the estimate because liquefaction features may not be observed at any given exposure of a stream bank, even though liquefaction occurred there. Some reasons for the absence of liquefaction features can include orientation of the exposure with respect to that of dikes, lateral movement of the fluidized sediment and water, and erosion of small lateral spreading features.

Field observations show that the bound in Figure 12 separating sites where liquefaction occurred from sites of no effects is surprisingly well defined (e.g, Liao, 1996), considering the practical difficulty in locating the source bed that liquefied. In fact, positive identification of the source bed is difficult to virtually impossible in many field settings. Figures 2 shows such an example, where a sill extends horizontally a long distance before venting to the surface. Here the sill runs beneath a 
mat of roots or peat. Similarly, as indicated in Figure 13, fluidized sediment can travel horizontally many meters beneath a sloping cap before venting, especially where channel-fill deposits are inset deeply into overbank deposits. Therefore, the possible role of the geologic setting and stratigraphy on surface manifestations of liquefaction must be carefully evaluated when trying to establish the source bed that liquefied (e.g, Obermeier, 1996b).

Some possible shortcomings in using the cyclic stress method for evaluating liquefaction potential have been discussed by Law et al. (1990), who suggested that energy is a more fundamental and accurate parameter for evaluating whether liquefaction should occur. Law et al. (1990) pointed out that (1) the peak acceleration in one direction does not always reflect the amount of energy acting on a point, and (2) the peak horizontal acceleration does not reflect what is happening at all vibration frequencies. In addition, the peak horizontal acceleration may relate poorly to shear strain, which is the physical mechanism that breaks down grain-to-grain contacts and leads to liquefaction. Also, the correspondence between shear strain and acceleration that is implicit in the cyclic stress liquefaction resistance relations may not be valid where surface shaking is unusually rich in very lowvibration frequencies, large shear strains, or low accelerations having a very long time duration. Use of the cyclic stress relations for such scenarios could lead to an over-estimate of the peak acceleration in back-analysis.

Historical evidence suggests that very thick (on the order of a kilometer), unlithified sediments, especially those with very soft clays of Tertiary age that underlie the Coastal Plain of South Carolina may dampen out higher frequency vibrations or cause them to be shifted to a significantly lower frequency as they propagate upward (Chapman et al., 1990), which could pose problems in interpretations with the cyclic stress method. Many coastal areas as well as large portions of the continental U.S. are underlain by unlithified Tertiary deposits that are extraordinarily thick and thus may be prone to this dampening or shifting of frequencies. More recently, Hashash and Park (in press) suggest that dampening may not occur in deep soil columns, even those of both fine- and coarse-grained sediments, and that a large majority of the bedrock motion may be transmitted up the column and available to trigger liquefaction. This result is in contrast to the common perception that high frequency vibration (greater than about 4 to $5 \mathrm{~Hz}$ ) is attenuated significantly during propagation through the soil column. Preliminary results indicate that when pressure-dependent are considered, spectral accelerations in the period range of 0.1 to 10 seconds may be up to $30 \%$ larger in a $100 \mathrm{~m}$ soil column and $500 \%$ larger in a $1000 \mathrm{~m}$ soil column than spectral accelerations calculated using conventional pressure-independent soil properties (Hashash and Park, in press).

Case history examples. There is a widespread perception that the cyclic stress method can yield only the minimum magnitude earthquake and acceleration that caused the observed paleoliquefaction effects. The cyclic stress method, however, can be used with the regional development of paleoliquefaction features to make a best-estimate of the earthquake magnitude and accelerations that caused them. The procedure for doing this, developed by Pond (1996), is shown in Figure 14 for the Wabash Valley region earthquake of 6,100 yr BP (the Vincennes earthquake in Table 3 ).

The curves (solid lines) in Figure 14 represent SPT $\left(\mathrm{N}_{1}\right)_{60}$ values for marginal liquefaction for various earthquake magnitudes, as a function of distance from the energy center. The curves were 


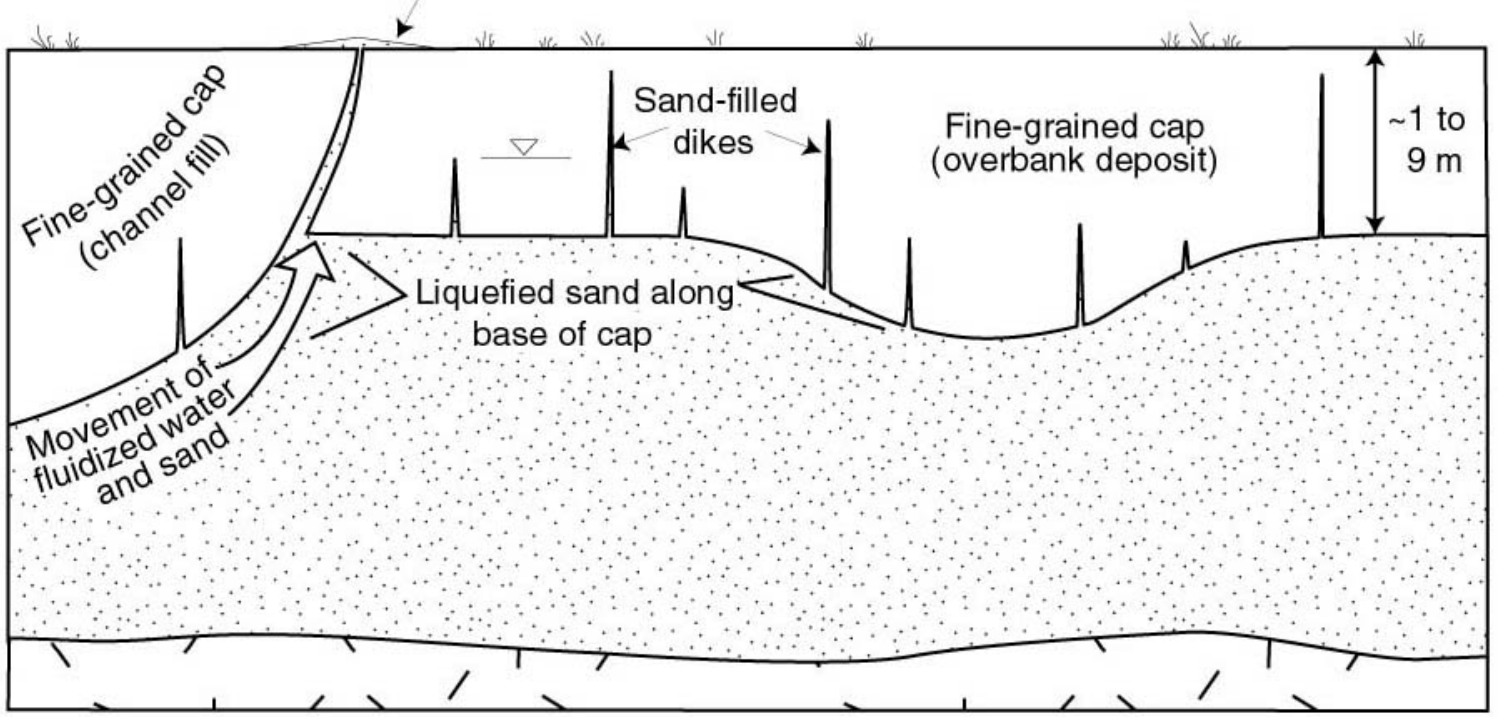

Figure 13. Vertical section showing field situation where venting occurs preferentially. Modified from Fiegel and Kutter (1994) amd Tuttle and Barstow (1996). 
$\$$

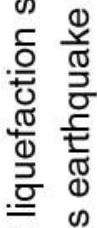

*

ఫृ

壱

(ฮ) $>$

ह ำ

d

은

80

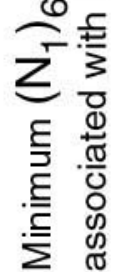

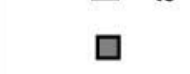

o

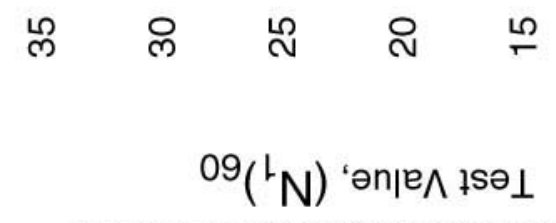

으

เ) 
developed by Pond (1996) using boundary relationships that are essentially those of Seed et al. (1985) base curve shown in Figure 12. The curves in Figure 14 were developed using the following steps: (1) use a bedrock ground motion-attenuation model to estimate the bedrock acceleration at a given distance from the earthquake energy center; (2) use a site-response program to determine the peak surface acceleration at a site located at that given distance from the energy center; (3) estimate the average cyclic stress ratio using the peak surface acceleration determined in step (2) and the desired earthquake magnitude; (4) read the $\left(\mathrm{N}_{1}\right)_{60}$ value that corresponds to the liquefaction resistance curve in Figure 12 for the cyclic stress ratio determined in step (3); and (5) repeat steps (1) through (4) for various distances from the energy center.

Figure 14 also shows data points as solid squares. The field sites for the back-calculations in this case-hist ory were chosen to reflect directionality of stronger shaking, and so the sites were located mainly near the Wabash River as well as White and Eel Rivers, north of Vincennes (Fig 9). Each data point corresponds to the minimum SPT $\left(\mathrm{N}_{1}\right)_{60}$ value measured in a geotechnical boring at a paleoliquefaction site. (At sites of widespread liquefaction where there were many dikes, and where several borings were conducted, the largest of the minimum values of $\left(\mathrm{N}_{1}\right)_{60}$ from the several borings was chosen as the data point for Figure 14.) At many sites the actual value of $\left(\mathrm{N}_{1}\right)_{60}$ that liquefied was almost certainly higher than the minimum value that is shown in Figure 14, and at many places considerably higher.

Pond(1996) selected the magnitude of the paleo-earthquake (M 7.7) on the basis of the highest magnitude indicated by a corresponding minimum blow count value. For Figure 14, a magnitude of M 7.7 is indicated from a site about $77 \mathrm{~km}$ from the energy center, and a value of $\mathbf{M} 7.6$ is indicated by a site at $79 \mathrm{~km}$ from the energy center. An overview of the magnitude using many sites relatively far from the energy center (which are the most reliable sites for this type of analysis, because high values of minimum blow counts do not exist at many sites near the energy center), strongly suggests at least $\mathbf{M}$ 7.5.

If Pond (1996) had used Figure 12 for the analysis, with the updated version of the Seed et al. (1985) liquefaction resistance curves and $\mathrm{P}_{\mathrm{L}}$ of $50 \%$, the interpreted magnitude would have been essentially the same. Similarly, using the updated relations in Youd and Idriss (1997) to scale for the influence of magnitude makes no significant difference because the back-calculated magnitude is near $\mathbf{M}$ 7.5. However, we note that if the back-calculated magnitude had differed much from $\mathbf{M}$ 7.5 (e.g, $\mathbf{M}<7$ or $\mathbf{M}>8$ ), the influence of scaling for magnitude would have been significant.

Pond (1996) made no corrections to account for effects of aging on liquefaction susceptibility at the sites of liquefaction, even though the SPT values were measured several thousand years after the liquefaction occurred. We suspect that the effects of aging probably would have reduced the value of $\left(\mathrm{N}_{1}\right)_{60}$ by no more than 1 or 2 for the typically moderately compact sediments of the region, and this small change would have little influence on the interpretation of paleomagnitude. We noted in a much earlier section in this paper that the maximum increase due to aging of very loose sediments in the region is likely a value of 3 to 4 , and that the increase in more compact sediments has probably been much lower because of the higher initial compactness. 
Whenever using the method illustrated in Figure 14 to select paleomagnitude, the possibility must be considered whether ground motions were improperly modeled by the site-response program, leading to misrepresentation of the actual level of shaking near the ground surface. This can occur due to inadequacies of shaking time-history relations (i.e., spectral accelerations) used to simulate the paleo-earthquake. Because the shaking characteristics of the paleo-earthquake are unknown, we suggest that the interpretation of paleomagnitude is best assessed by consideration of the regional pattern of back-calculated accelerations. We also suggest that a suite of "representative" earthquake time-histories be used to assess site response characteristics, rather than a single time-history. This practice is typically employed by earthquake engineers. These measures will reduce the possibility that the paleomagnitude interpretation is influenced by anomalous site response or bedrock time-history characteristics.

\section{Energy-Based Approaches}

Energy-based approaches to liquefaction analysis are inherently appealing because moment magnitude, $\mathbf{M}$, is a direct measure of seismic energy. Such approaches are all the more attractive because energy is a fundamental physical parameter. Still, energy-based approaches are not at the state of development to be used for routine analysis, although some will doubtlessly be so in the near future. This section briefly summarizes the developments in energy-based approaches that have received the most attention in recent years, points out their strengths and shortcomings, and also identifies conditions where they can be useful for paleoseismic analysis. Lastly, this section notes the most promising developments.

Our discussion below considers the following: (1) field case histories using the Gutenberg-Richter (1956) energy relation, (2) dissipated energy in laboratory tests, and (3) Arias Intensity as a measure of soil liquefaction resistance and the input of an earthquake.

Field case histories using Gutenberg-Richter relations. Davis and Berrill (1982) first developed an energy-based approach for predicting liquefaction from field data. Similar and extended approaches were later proposed by Berrill and Davis (1985), Law et al. (1990), and Trifunac (1995). The most recent compilation using data from Berrill and Davis (1985) and Trifunac (1995) is shown in Figure 15. The y-axis of the figure represents the combination of energy and stress conditions experienced at a site. The $\mathrm{x}$-axis represents sediment properties at the site, in terms of SPT $\left(\mathrm{N}_{1}\right)_{60}$. Two bounds are shown in Figure 15, separating sites of observed liquefaction from sites of no liquefaction; it is readily apparent that the bound of Trifunac (1995) differs substantially for that of Davis and Berrill (1985). Also, it is readily apparent from Figure 15 that regardless of whose bound is selected, there is considerable overlapping of sites of liquefaction with sites of no liquefaction.

Part of the scatter almost certainly originates from the use of the empirical Gutenberg-Richter (1956) function as a measure of radiated energy, E, defined as:

$$
E \approx \frac{10^{1.3 M}}{R^{2}}
$$

where $\mathbf{M}$ is moment magnitude, and Trifunac (1995) uses $\mathrm{R}$ as the epicentral distance, while Davis 
and Berrill (1985) use $\mathrm{R}$ as distance from the energy center. As pointed out by Trifunac (1995), much of the scatter is likely because the model does not account for seismic source mechanisms, directionality of strong motions, or local geologic conditions. It is also likely that part of the scatter is caused by use of epicentral distance rather than distance from the energy center, especially for larger earthquakes. Furthermore, Trifunac (1995) indicates that the function for E applies to body waves only, and thus cannot describe the attenuation of strong motions in the meizoseismal region, especially for larger earthquakes. However, we suggest that because body waves are dominant in the development of liquefaction, and because surface waves do not extend below shallow depths, they are unlikely to have much influence in the development of liquefaction at many places. Still, surface waves can play a large role in the breakup of a cap and determining whether venting takes place at the ground surface.

Because of these problems with the function E, paleoseismic analysis suffers from the same uncertainties that are inherent in both the cyclic stress method and the magnitude bound method, where effects of historical earthquakes are not available for local calibration. Other uncertainties involve whether the thickness of sediments and properties of those sediments cause attenuation of energy as it is transmitted up from bedrock. Going from bedrock up to the depth where the breakdown of grain-to-grain contact can become important (typically within several tens of meters of the ground surface), this change in energy is probably not a serious problem in most locales underlain by sands, even sands kilometers in thickness (unpublished data by Y. Hashash, Univ. of Illinois, 2000, written commun., using work and data in Assimaki, 2000, and in Laird and Stokoe, 1993), but may be a significant problem where soft clays exist at depth. For example, Chapman et al. (1990) found that in the Coastal Plain of South Carolina, which is underlain by kilometers of Tertiary deposits, some so soft that they appear freshly deposited, there may be significant dampening, especially of higher frequencies. Still, in general, except in regions of very strong seismic shaking, there is likely to be only minor loss of energy during propagation up through the sediment column to within several tens of meters of the surface. Even where the amount of energy is only slightly attenuated during upward propagation, the nature of the energy can be changed in frequency content, which can affect whether or not liquefaction occurs.

Near the ground surface, breakdown of the sediment grain-to-grain contacts may lead to a considerable loss of energy. This may be the case for some liquefiable deposits, and if so could be a serious source of error in using the function E for analysis. However, the cyclic stress method successfully uses "total stress" peak surface accelerations to evaluate liquefaction potential. "Total stress" in this context means that accelerations, stresses, etc. are not affected by local buildup of pore-water pressure (and concurrent degradation of shear modulus) that especially occurs in loose sands during seismic shaking, and also implies an absence of stresses due to any nearby man-made structures. The $\mathrm{E}$ function is also representative of a total stress condition, and similar to the cyclic stress method, the practical importance of errors resulting from local porewater pressure increase may be minor. Still, for the E function, the variation of $\mathrm{E}$ as a function of depth in the deposit is not accounted for in Figure 15 and for other approaches that are based on the Gutenberg-Richter relations, and there is no simple means for doing so.

Another problem in using the relations in Figure 15 to evaluate liquefaction potential relates to the energy capacity of a soil. Laboratory studies show that a fundamental relationship exists between dissipated energy and excess pore-water generation (Nemat-Nasser and Shokooh, 1979; 

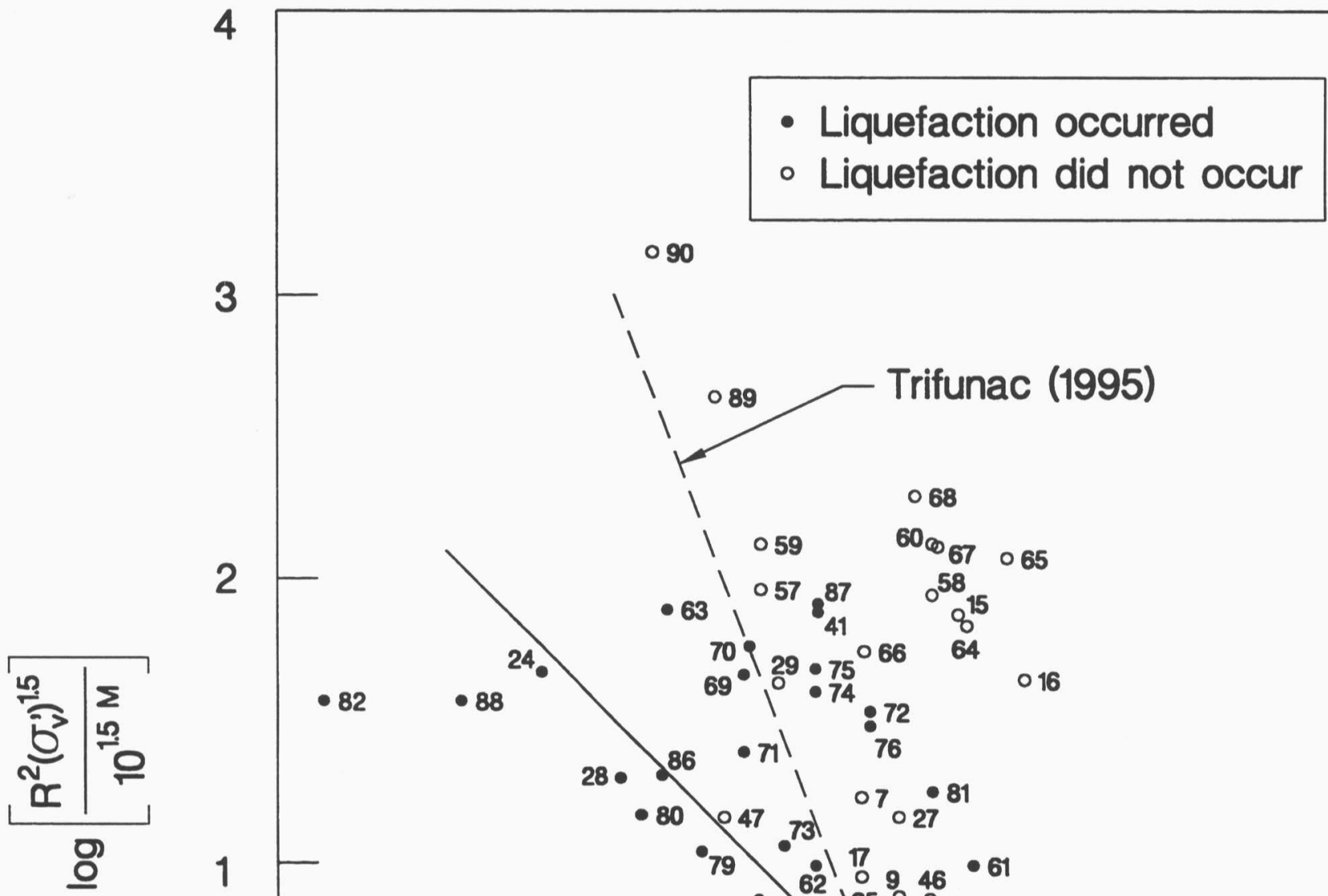

$\circ 90$

3
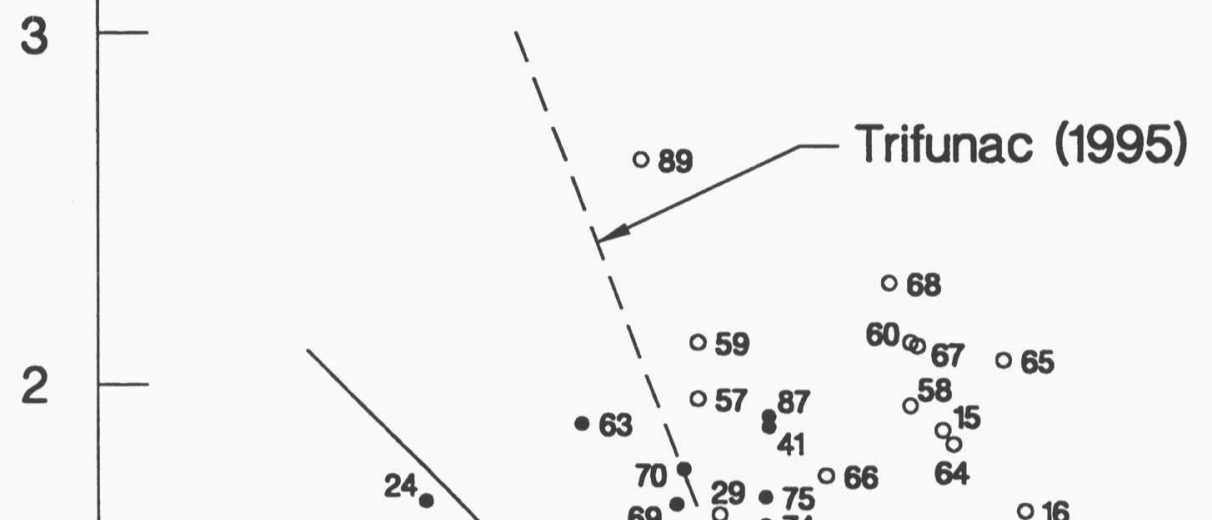

82

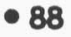

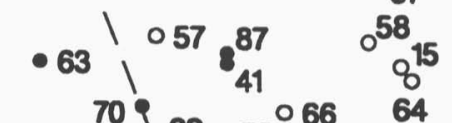

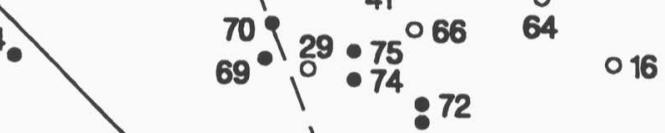

- 83
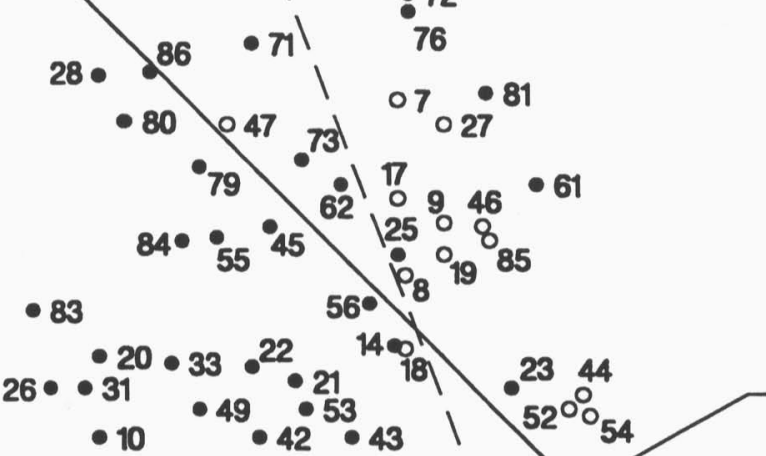

Berrill and

Davis (1985)

$\bullet 78$

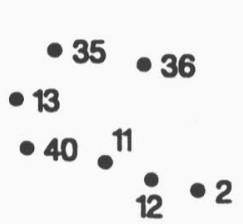

- 39 $50 \backslash$

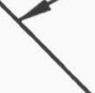
77 d

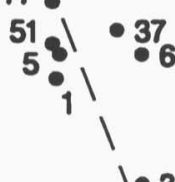

$1 \cdot 3$ $4 \div$

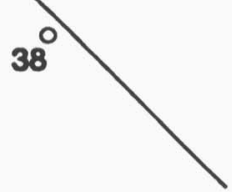

1

10

Figure 15. Energy-based liquefaction chart developed by Berrill and Davis (1985) using the Gutenberg-Richter energy relations to analyze eqrthquake case histories. Also shown is the liquefaction boundary developed by Trifunac (1995). (From Trifunac, 1995) 
Simcock, 1983; Liang et al., 1995; Green at al., 2000). Studies such as these justify employing energy as a measure of the ability of soil to resist liquefaction. However, the parameter E computed from the Gutenberg-Richter energy relation is a measure of total energy, and not dissipated energy. Therefore, the assumed functional relations that are used for Figure 15, which relate liquefaction to total energy, are too simple in their present state for routine liquefaction analysis.

Despite the problems noted above in relating the Gutenberg-Richter energy relations and the local field setting to liquefaction potential (i.e., Fig. 15), it seems likely that there are many settings for which such an approach can be used for paleoliquefaction analysis. Unfortunately, to date, there

have been no studies to identify those situations. Using available databases, a parametric study could likely clarify many of the conditions for which relations such as those in Figure 15 apply.

Pond (1996) attempted to circumvent some of the problems noted above by first relating the Gutenberg-Richter function to the SPT value of $\left(\mathrm{N}_{1}\right)_{60}$ required for liquefaction, without accounting for stress conditions in the field, and then used the Seed et al. (1985) liquefaction resistance relations to account for site specific conditions. Using such an approach, termed the "energy-stress" method, Pond (1996) back-calculated the magnitudes of the four largest paleoearthquakes in the Wabash Valley region (e.g, those listed in Table 3) and compared the results with back-calculations based on the magnitude bound and the cyclic stress methods. As shown in Table 3, all three methods yielded essentially the same values of magnitude for each of the four earthquakes.

Pond (1996) also has applied his method to well-documented, historical cases of liquefaction as well as cases of non-liquefaction. Eleven sites from four separate earthquakes were investigated. Seven sites were at locales of liquefaction, and four were at sites of no reported liquefaction. Pond's method correctly predicted the observations; back-calculated accelerations using the method agreed well with observed field values where available, and elsewhere agreed reasonably well with estimates using empirical relations. Still, Pond's (1996) technique does not account for stress conditions in the field to directly relate the Gutenberg-Richter function to liquefaction susceptibility, and therefore involves considerable uncertainty.

Laboratory test results. Laboratory testing has clearly demonstrated that a direct relation exists between dissipated energy and buildup of pore-water pressure during undrained cyclic shearing of saturated sands (Nemat-Nasser and Shokooh, 1979; Simcock et al, 1983; Liang et al., 1995; Green et al., 2000). Building on this observation, several researchers have attempted to use laboratory data to correlate normalized energy capacity (i.e., capacity per unit volume, accounting for influence of initial effective confining stress conditions) and relative density for various types of soils (e.g, Al-khatib, 1994; Ostadan et al. 1998). In these studies, normalized energy capacities were computed as the area bounded by the stress-strain hysteresis loops, up to the point of liquefaction. It is now well demonstrated that the normalized energy capacity is a fundamental parameter for evaluating the liquefaction potential of reconstituted samples that are tested in the laboratory. 
Reconstituted laboratory samples such as those used in the studies cited above cannot be used directly for evaluation of the liquefaction potential of naturally occurring samples in the field, because of differences in deposition, overconsolidation, pre-shearing, or aging (i.e., Terzaghi et al. 1996; Olson et al., 2001). This problem can be circumvented for important projects, including paleoseismic studies, by conducting the laboratory tests on undisturbed frozen samples. However,

obtaining undisturbed field samples is very expensive, and therefore this technique has seen limited use in practice.

Arias Intensity method. Kayen and Mitchell (1997) extended preliminary work of Egan and Rosidi (1991) and developed correlations to predict the occurrence of liquefaction as functions of the Arias Intensity of the earthquake motion and penetration resistance of the soil. Arias Intensity, $\mathrm{I}_{\mathrm{h}}$, is defined by the equation:

$$
I_{h}=I_{x x}+I_{y y}=\frac{\pi}{2 g} \int_{0}^{t} a_{x}^{2}(t) d t+\frac{\pi}{2 g} \int_{0}^{t} a_{y}^{2}(t) d t
$$

where $I_{x x}$ is the intensity value in the $x$-direction in response to transient motions in the $x$ direction and $\mathrm{I}_{\mathrm{yy}}$ is the intensity in the $\mathrm{y}$-direction, $\mathrm{g}$ is the acceleration due to gravity, $\mathrm{t}$ is the duration of shaking, and $\mathrm{a}_{\mathrm{x}}(\mathrm{t})$ and $\mathrm{a}_{\mathrm{y}}(\mathrm{t})$ are the transient accelerations of earthquake motion in the $\mathrm{x}$-and $\mathrm{y}$-directions, respectively. In this approach, the energy applied to the soil is:

$$
I_{h b}=\left(I_{x x}+I_{h h}\right) r_{b}
$$

where $r_{b}$ is a depth reduction factor that accounts for the variation of Arias intensity with depth.

However, this technique does not explicitly account for the influence of effective confining pressure (e.g, depth of water table). And, as Trifunac (1999) noted, there are basic questions concerning whether the Arias Intensity function represents the actual energy input into an element of soil. Still, the correlations that Mitchell and Kayen (1997) developed appear very good and may be suitable for paleoliquefaction analysis in field situations where the water table was shallow at the time of the earthquake. Acceleration time-history relations that can be used to express Arias Intensity as a function of earthquake magnitude and site-to-source distance are currently available for only a few regions of the world, but this problem possibly may be avoided using Arias Intensity attenuation relationships suggested by Kayen and Mitchell (1997) for the western U.S. and as used tentatively by Schneider (1999) in the central U.S.

\section{Ishihara Method}

For paleoseismic analysis, the Ishihara (1985) method is a technique to estimate peak accelerations at sites of paleoliquefaction. The premise of the method is that the maximum height of dikes (accompanied by venting at the surface) is controlled by two factors: the thickness of liquefied sediment and the peak acceleration (Fig 6). Ishihara (1985) originally developed the bounds in Figure 6 using data from only a few earthquakes with magnitudes on the order of $\mathbf{M} \sim 7.5$ and higher. Only limited data have since been added for such large earthquakes. Youd and Garris (1995) showed that the method is not valid for ground failure from lateral spreading or surface 
oscillations, but only for the mechanism of hydraulic fracturing, and even then under constrained conditions. The relationships in Figure 6 for the Ishihara method probably represent sites where surface effects of liquefaction from hydraulic fracturing were abundant, i.e., liquefaction was severe (T.L. Youd, Brigham Young Univ., 1998, oral commun.).

The range of relative densities of liquefied sand for which the Ishihara (1985) method applies is not well established, but for $\mathbf{M} \sim 7.5$ and higher the method appears to be valid for sands with SPT $\mathrm{N}$-values as high as 20 (moderately compact, Table 1), according to data in Ishihara (1985, p. 361-362).

Youd and Garris (1995) examined effects of twenty-seven earthquakes ranging from $\mathbf{M} 5.3$ to 8 , and concluded that throughout this range of magnitudes the bounds proposed by Ishihara (1985) place a reasonable upper limit to the thickness of cap cut through by dikes (due to hydraulic fracturing). The actual thickness cut through by hydraulic fracturing is often much less than indicated by the curves in Figure 6. A more recent finding (T.L. Youd, Brigham Young Univ., 1998, oral commun.) is that the Ishihara (1985) method seems to reasonably predict the thickness of caps cut through by hydraulic fracturing for very loose source sands only ( $\mathrm{N}$-values of 4 or less, Table 1), at least for the earthquakes for which adequate data were available to fully critique the method (i.e., earthquakes of $\mathbf{M} 6.5$ and lower). Source sands with higher relative densities cut through smaller heights.

Pease and O'Rourke (1995) also critiqued the Ishihara (1985) method for the M 7.1 Loma Prieta earthquake of 1989, and they found the Ishihara method correctly predicted occurrences of surface effects of liquefaction except at sites of lateral spreading or surface oscillations. Pease and O'Rourke (1995) did not present detailed data concerning the properties of the liquefied source sands, but most appear to have been loose and some moderately compact.

Why the Ishihara (1985) method may work is unclear, but our state of understanding is as follows. The height that a dike intrudes into the cap is controlled partly by the pore pressure change in the water upon liquefaction and partly by the amount of water available (Dobry, 1989). The pore pressure change relates indirectly to cap thickness because as the cap thickness increases, the depth to the top of potentially liquefiable sand increases. This increases the effective confining stress at the top of the sand bed (see Fig. 16). The higher effective confining stress requires a higher shear stress (acceleration) to induce liquefaction, which, in turn, also requires a greater pore-water pressure change to trigger liquefaction; the greater increase in pore pressure can hydraulically fracture a greater cap thickness.

Other factors are involved in determining the height of dikes. Figure 6 shows that for a given thickness of liquefied sediment, the height of dikes also depends on the peak acceleration. The importance of peak acceleration may relate to a number of factors. Most likely possibilities include: (1) a higher acceleration induces higher shear stresses; (2) a higher acceleration is more likely to cause breakage of the cap, irrespective of hydraulic fracturing; (3) a higher acceleration may be associated with a longer duration of strong shaking; and (4) a higher acceleration is more likely to induce a greater thickness of liquefied sediment, providing more water for hydraulic fracturing. The last two points above may apply especially to more compact sediments because 
they may not liquefy completely except in very large earthquakes (for which a longer duration of strong shaking typically occurs).

Field situations where there is a concentration of flow beneath the cap, such as that illustrated in Figure 13, are suspect for interpretation using the Ishihara (1985) method. Figure 13 illustrates that upon liquefaction, water and suspended sediment tend to be forced upward along the base of the fine-grained channel-fill in the steeply dipping portions. Liquefaction features thereby occur at the surface where the channel-fill comes in contact with the thinner overbank deposit.

To summarize, the Ishihara (1985) method may be applicable where the cap thickness is reasonably uniform (or at least does not slope much along its base) and for source sands ranging from very loose to moderately compact, at least for $\mathbf{M} \sim 7.5$ or larger earthquakes. For lower magnitudes, the method likely applies only for loose deposits. More detailed data regarding sitespecific parameters are needed to critique the method more fully.

The Ishihara (1985) method has great potential for paleoseismic analysis at sites where the ground failure can be attributed confidently to hydraulic fracturing. The method is ideally suited for using measurements of dike height and cap thickness, which are observable along many stream banks.

\section{S UMMARY AND CONCLUDING COMMENTARY}

Extensive field studies show that the paleoliquefaction record for a region commonly extends back through much of Holocene time and into the latest Pleistocene. The liquefaction susceptibility of many deposits has diminished little or at least not greatly so since initial deposition. A typical setting for the formation of liquefaction features through time is in a valley of a moderate to large river, on the modern flood plain or on a terrace that is a few meters higher, where the depth to the water table typically has been several meters or less and where thick sand deposits abound. Such field settings are plentiful within the glaciated portions of the central U.S. and far southward in their glaciofluvial drainages. Even beyond the limits of these glacial effects, in the semi-tropical southeastern U.S., river banks that have cut into low-lying terraces commonly expose liquefiable sediments dating far back in time, with portions going back into the Pleistocene. In the coastal regions of the southeastern U.S., within $30 \mathrm{~km}$ or so of the ocean, there are numerous Pleistocene beach ridges comprised of thick liquefiable sands. Huge swamps have developed behind many of these ridges, maintaining a high water table through time. Manmade drainages cut into these ridges to drain the swamps frequently expose any effects of liquefaction. Overall, throughout most of the central and southeastern U.S., liquefiable deposits are spaced close enough to reveal the occurrence of any very large earthquakes (say, $\mathbf{M} 7.5$ or higher) that would have struck throughout most of Holocene time. And, much smaller earthquakes would have left manifestations of liquefaction at many places.

The extensive reliance on paleoliquefaction studies in the central and eastern U.S. is due partly to the abundance of stream valleys in this humid environment containing liquefiable deposits. In a similar vein, it has been found that such liquefiable deposits occur throughout much of the humid and rainy Pacific Northwest, revealing the paleoseismic record through at least a significant portion of Holocene time (Obermeier and Dickenson, 2000). However, adequate streams are 
available for paleoliquefaction studies even in many arid conditions. Overall, throughout much of the U.S. and in many field settings worldwide, there are sufficient liquefiable deposits to reveal the record of strong Holocene seismicity.

Paleoliquefaction searches are generally best conducted where exposures can be seen in the vertical section, such as along stream banks, drainage ditches, and borrow pits. This is especially so where an earthquake occurred thousands of years ago and the surface evidence of liquefaction has been buried or destroyed. Evidence of liquefaction in vertical section includes steeply-dipping dikes, horizontal sills, bowl-shaped intrusions, craterlets, and other similar features. A seismic origin to these features can be verified using the stringent criteria presented by Obermeier (1996a). A useful paleoliquefaction search requires examining many kilometers of exposures at scattered places over a region at least tens of kilometers in radius, and over a much larger region in most locales.

Guidelines for the conduct of a paleoliquefaction search have been discussed herein, as well as in Obermeier (1996a) and Obermeier and Pond (1999). A paleoliquefaction search should preferably identify the following information for back-analysis of strength of shaking and magnitude: (1) the causative mechanism that formed the feature(s), i.e., lateral spreading, hydraulic fracturing, and/or surface oscillations; (2) the thickness of the fine-grained cap (if present) overlying the source bed; (3) the probable source bed and its properties such as grainsize distribution and penetration resistance; (4) the depth to the water table at the time of liquefaction; (5) the approximate age of the feature (using archeological techniques, soil pedology, and/or radiocarbon dating); (6) the approximate dimensions of the feature(s); and (7) the possible effects of aging, chemical deposition (cementation) or alteration, and/or weathering on liquefaction susceptibility. Wherever possible, the search should be conducted in a variety of field settings in order to enhance confidence in back-calculations of seismic parameters.

After conducting a paleoliquefaction search, three questions always arise when using liquefaction features for paleoseismic analysis: Where was the tectonic source? What was the magnitude? And what was the strength of shaking? Credible answers to these questions have been provided by liquefaction studies in many parts of the central and eastern U.S.

In fluvial deposits commonly encountered in the central and eastern U.S., the size and regional pattern of liquefaction features serve as excellent indicators of whether strong, prehistoric seismic shaking occurred. The technique of using maximum dike width or some other liquefaction effect often can be used to estimate the location of the prehistoric tectonic (energy) source, especially where field settings abound that are similar in terms of liquefaction susceptibility and site amplification.

More than one method is available to quantitatively estimate the magnitude of a paleoearthquake, thereby permitting cross-checking of back-calculations in many field settings. It is our opinion that when used in conjunction with the regional pattern of liquefaction development and acceleration attenuation, the cyclic stress method can provide a reasonable assessment of both earthquake magnitude and surface accelerations, at least in terms of hazard assessments. To have much confidence in back-calculations using the cyclic-stress method, 
however, may require a regional perspective that uses data from many sites. Whenever possible, it is preferable to do back-calculations in various types of field settings, where factors such as liquefaction susceptibility and site amplification vary, and highly so, because there is often uncertainty in interpretations whenever only one type of field setting is used. In addition, the use of both sites of liquefaction and sites of no liquefaction effects can be especially useful for bounding the levels of shaking. At sites of liquefaction effects there is often a question of whether the occurrence of liquefaction has substantially altered the liquefaction susceptibility (Olson et al., 2001), whereas at sites of no liquefaction can be less of an issue.

Even where the back-calculated values agree using different techniques, such as the cyclic stress and magnitude bound methods, there can be some uncertainty because of the unknown influence of seismic parameters such as stress-drop and hypocentral depth. This can be particularly true where definitive data from strong historical earthquakes are not available for calibration. But common-sense guidelines can be very useful, as in the example of the Wabash Valley region of Indiana-Illinois where back-calculated magnitudes using both the magnitude bound and the cyclic stress methods yield $\mathbf{M} \sim 7.5$ for an earthquake that struck about 6,100 yr BP. Liquefaction features from that earthquake developed at distances of up to $170 \mathrm{~km}$ from the source region (i.e., the energy center). Using the range of liquefaction effects from earthquakes worldwide as a basis for comparison, and, in consideration that the sediments in the Wabash Valley region were typically only moderately susceptible to liquefaction (using the definition of moderate susceptibility discussed in this paper), it is reasonable to conclude that the earthquake probably was considerably in excess of $\mathbf{M} 7$. The liquefaction effects indicate that the earthquake of $6,100 \mathrm{yr}$ BP had the destructive effects of an earthquake that is typically associated with a magnitude of $\mathbf{M} \sim 7.5$ or higher.

The severity of liquefaction effects alone can also provide important clues about the severity of shaking. For the earthquake of $6,100 \mathrm{yr}$ BP, dikes from lateral spreading were up to $2.7 \mathrm{~m}$ wide and numerous dikes exceeded $0.7 \mathrm{~m}$ in width; the thickness of vented sand and gravel was up to $0.3 \mathrm{~m}$ at widespread places. All these liquefaction effects suggest very strong shaking.

Alternatively, where the widest dikes that are discovered in an extensive regional search of liquefiable deposits locates dikes no wider than about $0.3 \mathrm{~m}$, no more than a moderate level of shaking (very probably less than $1 / 2 \mathrm{~g}$, especially for larger magnitude earthquakes) is suggested if the sediments that liquefied were loose to moderately compact sands. Similarly, if the thickness of vented sand through a thin fine-grained cap (say, 1 to $2 \mathrm{~m}$ thick) was only a few centimeters, and the sediment that liquefied was a thick, loose to moderately compact sand, relatively weak shaking is again suggested. Or, if a cap only 1 to $2 \mathrm{~m}$ thick was adequate to prevent widespread and commonplace venting to the surface, and thick, moderately compact or looser sands underlie the cap, no more than a moderate level of shaking is suggested.

Energy-based calculations offer great possibilities for avoiding uncertainties in back-calculations, caused by the lack of knowledge about the effect of seismic parameters such as focal depth and stress drop. At present, the only means of making such calculations is by laboratory testing and analysis of undisturbed samples. Collection of undisturbed samples for this type of analysis is very expensive and difficult. Energy-based techniques that utilize field measurements of penetration 
resistance are not yet adequately developed to provide much confidence in back-calculations, but probably can be developed with further research.

Paleoliquefaction studies in the central and eastern U.S. also have been used to show a lack of strong shaking through much of Holocene time in many places. Reasonable upper limits of prehistoric peak accelerations and magnitudes often can be established in regions having no liquefaction features. And, sufficient exposures occur in many regions to permit detection of liquefaction effects had they been produced by any nearby strong earthquakes. For example, for a $\mathbf{M}>7$ earthquake, and field conditions only moderately susceptible to liquefaction, dikes should almost certainly develop considerably farther than 30 to $50 \mathrm{~km}$ from the tectonic (energy) center in the eastern and central U.S. (see Fig. 10).

The use of paleoliquefaction studies to unravel the prehistoric seismic record continues to be relied on heavily in the central and eastern U.S. This reliance results in part from of the overall lack of exposures that might reveal faults, but increasingly because knowledge is becoming widespread of the successes of back-analyses in those areas. The studies in the eastern and central U.S. typically have involved close cooperation among geologists, archeologists, soil scientists, and geotechnical engineers, both during the field study and while making interpretations, and these combined efforts have proven extremely successful (e.g, Martin and Clough, 1994; Munson et al., 1995, 1997; McNulty and Obermeier, 1999; Obermeier, 1996a, 1998a; Pond, 1996; Tuttle, 1999).

The interpretation of liquefaction features for paleoseismic analysis has not met with widespread acceptance in some areas outside the central and eastern U.S. Liquefaction studies are little used in regions where surface faults are present to study. Also, whereas searching for liquefaction features and interpreting a seismic origin is relatively straightforward in many field settings, using liquefaction effects to interpret the strength of prehistoric shaking is quite another matter. A strong background in geotechnical engineering and seismology is required to assess the strength of shaking. Furthermore, a sound knowledge of the processes controlling liquefaction and its field manifestations is necessary.

An example of an area where an extensive paleoliquefaction study has the potential to be especially beneficial is in the Pacific Northwest of the U.S. Although it is clear that great subduction earthquakes strike there periodically, the strength of their shaking is not yet well bounded. Preliminary studies at sites of paleoliquefaction indicate that peak onshore accelerations from the subduction earthquakes, likely of about M 8-9 (Atwater and Hemphill-Haley, 1997; Nelson et al., 1995), were not especially strong (Obermeier, 1995; Obermeier and Dickenson, 2000). A paleoseismic study with extensive geotechnical input could almost certainly help resolve the issue of the actual strength of shaking 300 years ago, and also throughout Holocene time, by resorting to exposures available near the coasts of Washington and Oregon.

\section{AC KNO W LEDGMENTS}

The section titled Energy-Based Approaches is based in large part on ongoing research at Virginia Tech by Russell Green, under the direction of Prof. James K. Mitchell, whose research was funded by the Multi-Disciplinary Center for Earthquake Engineering Research Center. The funding for Scott Olson and Prof. Timothy Stark was provided by the National Science Foundation (NSF), 
Grant Number 97-01785, as part of the Mid-America Earthquake (MAE) Center, headquartered at the University of Illinois at Urbana-Champaign. The support of these organizations is gratefully acknowledged.

\section{REFERENCES CITED}

Al-khatib, M., 1994, Liquefaction assessment by strain-energy approach, Ph.D. Thesis, Wayne State University, Detroit, $212 \mathrm{p}$.

Allen, J.R.L., 1982, Sedimentary Structures - Their Character and Physical Basis, Amsterdam, Elsevier, v. 2, 663 p.

Ambraseys, N.N., 1988, Engineering seismology: Earthquake Engineering and Structural Dynamics, Elsevier Science, v. 17, p. 1-105.

Andrus, R.D., 1994, In Situ characterization of gravelly soils that liquefied in the 1983 Borah Peak earthquake: $\mathrm{Ph}$. D. Thesis, Univ. of Texas, Austin, 533 p.

Assimaki, D., 2000, Frequency and pressure dependent dynamic soil properties for seismic analysis of deep sites: M.S. Thesis, Department of Civil and Environmental engineering MIT, Cambridge, Massachusetts.

Atkinson, G.M., and Boore, D.M., 1995, Ground motion relations for eastern North America: Bulletin of the Seismological Society of America, v. 74, no. 6, p.17-30.

Atwater, B.F., and Hemphill-Haley, E., 1997, Recurrence intervals for great earthquakes of the past 3,500 years at northeastern Willapa Bay, Washington: U.S. Geological Survey Prof. Paper $1576,108 \mathrm{p}$.

Audemard, F., and de Santis, F., 1991, Survey of liquefaction structures induced by recent moderate earthquakes: Bulletin of the International Association of Engineering Geologists, no. 44 , p. 5-16.

Bartlett, S.F., and Youd, T.L., 1992, Empirical analysis of horizontal ground displacement generated by liquefaction-induced lateral spreads: Technical Report NCEER-92-0021, State University of New York at Buffalo, variously paged.

Bennett, M.J., 1989, Liquefaction analysis of the 1971 ground failure at the San Fernando Juvenile Hall: Bulletin of the Association of Engineering Geologists, v. 26, no. 2, p. 209-226.

Berrill, J.B., and Davis, R.O., 1985, Energy dissipation and seismic liquefaction of sands - revised model: Soils andFoundations, Japanese Society of Soil Mechanics and Foundation Engineering v. 25 , p. $106-118$.

Boore, D.M., and Joyner, W.B., 1991, Estimation of ground motion at deep soil sites in eastern north America: Bulletin of the Seismological Society of America, v. 81, no. 6, p. 2167-2185. 
Boulanger, R.W., Mejia, L.H., and Idriss, I.M., 1997, Liquefaction at Moss Landing during Loma Prieta earthquake: Journal of Geotechnical Engineering American Society of Civil Engineers, v. 123 , no. 5 , p. $453-467$.

Carter, D.P., and Seed, H.B., 1988, Liquefaction potential of sand deposits under low levels of excitation: Report No. UCB/EERC-81/11, College of Engineering Univ. of California, Berkeley, $119 \mathrm{pp}$.

Castro, G., 1987, On the behavior of soils during earthquakes - Liquefaction: Soil Dynamics and Liquefaction, A.S. Cakmak, ed., Elsevier, New York, p. 169-204.

Castro, G., 1995, Empirical methods in liquefaction analysis: Proceedings of the First Leonardo Zeevaert Conference, Mexico City, p. 1-41.

Chapman, M.C., Bollinger, G.A., Sibol, M.S., and Stephenson, D.E., 1990, Investigation of anomalous earthquake intensity levels along the Coastal Plain-Piedmont boundary in South Carolina and Georgia: Earthquake Spectra, v. 6, p. 617-640.

Davis, R.O., and Berrill, J.B., 1982, Energy dissipation and seismic liquefaction in sands: Earthquake Engineering and Structural Dynamics, Elsevier Science, v. 10, p. 59-68.

Dobry, R., 1989, Some basic aspects of soil liquefaction during earthquakes: Earthquake Hazards and the Design of Constructed Facilities in the Eastern United States, K.H. Jacob and C.J. Turkstra, eds., Annals of the New York Academy of Sciences, v. 558, p.172-182.

Egan, J.A., and Rosidi, D., 1991, Assessment of earthquake-induced liquefaction using groundmotion energy characteristics: Pacific Conference on Earthquake Engineering Nov. 20-23, New Zealand, p. 313-324.

Fiegel, G.L., and Kutter, B.L., 1994, Liquefaction mechanism for layered soils: Journal of Geotechnical Engineering American Society of Civil Engineers, v. 120, p. 737-755.

Gilstrap, S.D., 1998, CPT based liquefaction resistance analysis evaluated using case histories: M.S. Thesis, Brigham Young University, Provo, Utah, 304 p.

Green, R.A., Mitchell, J.K., and Polito, G., 2000, An energy-based pore pressure generation model for cohesionless soils: Proceedings of the John Booker Memorial Symposium, Sydney, Australia, Nov. 16-17, 2000.

Gutenberg, B., and Richter, C., 1956, Magnitude and energy of earthquakes: Annali de Geofisica, v. 9, p. 1-15.

Hanks, T.C., and Johnston, A.C., 1992, Common features of the excitation and propagation of strong ground motion for North American earthquakes: Bulletin of the Seismological Society of America, v. 82, p.1-23. 
Harder, L.F., and Seed, H.B., 1986, Determination of penetration resistance for coarse-grained soils using the Becker hammer: Earthquake Engineering Research Center, Report No. EERC86/06, Univ. of California, Berkeley.

Hashash, Y.M.A., and Park, D., in press, Non-linear one-dimensional seismic ground motion propagation in the Mississippi Embayment: Engineering Geology.

Holzer, T.L., Bennett, M.J., Ponti, D.J., and Tinsley, J.C., 1999, Liquefaction and soil failure during the 1994 Northridge earthquake: Journal of Geotechnical and Geoenvironmental Engineering American Society of Civil Engineers, v. 125, no. 6, p. 438-452.

Idriss, I.M., and Sun, J.I., 1992, : User's manual for SHAKE91. A computer program for conducting equivalent linear seismic response analyses of horizontally layered soil deposits: Center for earthquake modeling, University of California at Davis.

Ishibashi, I., and Zhang, X., 1993, Unified dynamic shear moduli and damping ratios of sand and clay: Soils and Foundations, Japanese Society of Soil Mechanics and Foundation Engineering v. 33, no. 1, p. 182-191.

Ishihara, K., 1985, Stability of natural soils during earthquakes, Proceedings of the Eleventh International Conference on Soil Mechanics and Foundation Engineering San Francisco, 1985, A.A. Balkema, Rotterdam/Boston, v. 1, p. 321-376.

Ishihara, K., 1993, Liquefaction and flow during earthquakes, Geotechnique, v. 43, no. 3, p. 351415.

Johnston, A.C., 1996, Seismic moment assessment of earthquakes in stable continental regionsIII. New Madrid 1811-1812, Charleston 1886 and Lisbon 1755: Geophysical Journal International, v. 124, p.314-344.

Johnston, A.C., and Schweig, E.S., 1996, The enigma of the New Madrid earthquakes of 18111812: Annual Review of Earth and Planetary Sciences, v. 24, p. 339-384.

Kayen, R.E., and Mitchell, J.K., 1997, Assessment of liquefaction potential during earthquakes by Arias intensity: Joumal of Geotechnical and Geoenvironmental Engineering American Society of Civil Engineers, v. 123, p.1162-1174.

Krinitzsky, E.L., and Chang, F.K., 1988, Intensity-related earthquake ground motions: Bulletin of the Association of Engineering Geologists, v. 24, p. 425-435.

Law, K.T., Cao, Y.L., and He, G.N., 1990, An energy approach for assessing liquefaction potential: Canadian Geotechnical Journal, v. 27, p.320-329. 
Laird, J.P., and Stokoe, K.H., 1993, Dynamic properties of remolded and undisturbed soil samples tested at high confining pressures: Engineering Report GR93-6, Electrical Power Research Institute.

Liang, L., Figueroa, J.L., and Saada., A.S., 1995, Liquefaction under random loading - unit energy approach: Journal of Geotechnical Engineering American Society of Civil Engineers, v. 121, p. 776-781.

Liao, S.S.C., 1996, Discussion of "Reconsideration of initiation of liquefaction in sandy soils": Journal of Geotechnical Engineering American Society of Civil Engineers, v. 22, p. 957-959.

Lo, K.Y., and Kaniaru, K., 1990, Hydraulic fracture in earth and rock-fill dams: Canadian Geotechnical Journal, v. 27,p. 496-506.

Lowe, D.R., 1975, Water escape structures in coarse-grained sediments: Sedimentology, v. 22, p.157-204.

Martin, J.R., and Clough, G.W., 1994, Seismic parameters from liquefaction evidence: Journal of Geotechnical Engineering American Society of Civil Engineers, v. 120, p. 1345-1361.

McCalpin, J.P., 1996, Paleoseismology: Academic Press, San Diego, 588 p.

McNulty, W.E., and Obermeier, S.F., 1999, Liquefaction evidence for at least two strong Holocene paleo-earthquakes in central and southwestern Illinois, USA: Environmental and Engineering Geoscience, vol. V, no. 2, p. 133-146.

Meier, L.S., 1993, The susceptibility of a gravelly soil site to liquefaction: M.S. Thesis, Virginia Polytechnic Institute, Blacksburg, Virginia, 74 p.

Mesri, G., Feng T.W., and Benek, J.M., 1990, Postdensification penetration resistance of clean sands: Journal of Geotechnical Engineering American Society of Civil Engineers, v. 116, no. 7, p. 1345-1361.

Metzger, A. G., 1996, "New" historical earthquakes in the New Madrid seismic zone: Seismological Research Letters, v. 76, p. 47 (abstract).

Munson, P.J., and Munson, C.A., 1996, Paleoliquefaction evidence for recurrent strong earthquakes since 20,000 yr BP in the Wabash Valley area of Indiana: Final report, submitted to the U.S. Geological Survey, March, 1996, 137 p.

Munson, P.J., Munson, C.A., and Pond, E.C., 1995, Paleoliquefaction evidence for a strong Holocene earthquake in south-central Indiana: Geology, v. 23, p. 325-328.

Munson, P.J., Obermeier, S.F., Munson, C.A., and Hajic, E.R., 1997, Liquefaction evidence for Holocene and latest Pleistocene seismicity in the southern halves of Indiana and Illinois: A preliminary interpretation: Seismological Research Letters, v. 68, p. 521-536. 
National Research Council, 1985, Liquefaction of soils during earthquakes: National Academy Press, Washington, DC, $240 \mathrm{p}$.

Nelson, A.R., Atwater, B.F., Bobrowsky, P.T., Bradley, L.A., Clague, J.J., Carver, G.A., Darienzo, M.K., Grant, W.C., Kruger, H.W., Sparks, R., Stafford, T.W., and Stuiver, M., 1995, Radiocarbon evidence for extensive plate-boundary rupture about 300 years ago at the Cascadia subduction zone, Nature, v. 378, p. 371-374.

Nemat-Nasser, S., and Shokooh, A., 1979, A unified approach to densification and liquefaction of cohesionless sand in cyclic shearing: Canadian Geotechnical Journal, v. 16, p. 659-678.

Nuttli, O.W., 1973, The Mississippi Valley earthquakes of 1811 and 1812; intensities, ground motion, and magnitudes: Bulletin of the Seismological Society of America, v. 73, p. 227-248.

Obermeier, S.F., 1989, The New Madrid earthquakes - An engineering-geologic interpretation of relict liquefaction features: U.S. Geological Survey Professional Paper 1336-B, 114 p.

Obermeier, S.F., 1993, Paleoliquefaction features as indicators of potential earthquake activity in the southeastern and central United States: Highway Research Board Record No. 1411, Highway Research Board, Washington, D.C., p. 42-52.

Obermeier, S.F., 1994, Using liquefaction-induced features for paleoseismic analysis, in Using ground failure features for paleoseismic analysis, Obermeier, S.F., and Jibson, R.W. eds., U.S. Geological Survey Open-File Report 94-663, Chapter A, 98 p.

Obermeier, S.F., 1995, Preliminary estimates of the strength of prehistoric shaking in the Columbia River valley and the southern half of coastal Washington, with emphasis for a Cascadia subduction zone earthquake about 300 years ago: U.S. Geological Survey Open-File Report 94$589,46 \mathrm{p}$.

Obermeier, S.F., 1996a, Use of liquefaction-induced features for paleoseismic analysis - An overview of how seismic liquefaction features can be distinguished from other features and how their regional distribution and properties of source sediment can be used to infer the location and strength of Holocene paleo-earthquakes: Engineering Geology, v. 44, p.1-76.

Obermeier, S.F., 1996b, Discussion of "Reconsideration of liquefaction in sandy soils": Journal of Geotechnical Engineering American Society of Civil Engineers, v. 122, p. 956-957.

Obermeier, S.F., 1998a, Overview of liquefaction evidence for strong earthquakes of Holocene and latest Pleistocene ages in the states of Indiana and Illinois, USA: Engineering Geology, Elsevier Science, v. 50, p. 227-254.

Obermeier, S.F., 1998b, Seismic liquefaction features - Examples from paleoseismic investigations in the continental United States: U.S. Geological Survey Open-File Report 98-488, CD-ROM 
Obermeier, S., Brack, J., Van Arsdale, R., and Olson, S., 2000, Depth of water table for paleoseismic back-calculations: GSA Abstracts with Programs, v. 23, no. 7, GSA Annual Meeting, Denver, Colorado, Nov., 2000.

Obermeier, S.F., and Dickenson, S.E., 2000, Liquefaction evidence for the strength of ground motions resulting from late Holocene Cascadia subduction earthquakes, with emphasis on the event of 1700 AD: Bulletin of the Seismological Society of America, v. 90, no. 4., p. 876-896.

Obermeier, S.F., Martin, J.R., Frankel, A.D., Youd, T.L., Munson, P.J., Munson, C.A., and Pond, E.C., 1993, Liquefaction evidence for one or more strong Holocene earthquakes in the Wabash Valley of southern Indiana and Illinois: U.S. Geological Survey Professional Paper 1536, 27 p.

Obermeier, S.F., and Pond, E.C., 1999, Issues in using liquefaction features for paleoseismic analysis: Seismological Research Letters, v. 70, p. 34-58.

Olson, S.M., Obermeier, S.F., and Stark, T.D., 2001, Interpretation of penetration resistance for back-analysis at sites of previous liquefaction: Seismological Research Letters, v. 72, no. 1, p. 4659.

Ostadan, F., Deng N., and Arango, I., 1998, Energy-based method for liquefaction potential evaluation: European Earthquake Engineering Conference, Sept. 6-11, Paris, France, A.A. Balkema, Rotterdam.

Pease, J.W., and O'Rourke, T.D., 1995, Liquefaction hazards in the San Francisco Bay region: Site investigation, modeling, and hazard assessment at areas most seriously affected by the 1989 Loma Prieta earthquake: Final report submitted to the U.S. Geological Survey, Cornell Univ., School of Civil and Environmental Engineering Ithaca, New York, 176 pp.

Perlea, V.G., Koester, J.P., and Prakash, S. (1999). How liquefiable are cohesive soils?: Proc., $2^{\text {nd }}$ Int. Conf. on Earthquake Geotechnical Engineering, Lisbon, Portugal, v. 2, p. 611-618.

Pond, E.C., 1996, Seismic parameters for the central United States based on paleoliquefaction evidence in the Wabash Valley, Ph. D. Thesis, Virginia Polytechnic Institute, Blacksburg, Virginia, $583 \mathrm{pp}$.

Rhea, S., and Wheeler, R.L., 1996, Map showing seismicity in the vicinity of the lower Wabash Valley, Illinois, Indiana, and Kentucky: U.S. Geological Survey Miscellaneous Investigation Map I2583-A, scale $1: 250,000$.

Robertson, P.K., and Wride, C.E., 1997, Cyclic liquefaction and its evaluation based on the SPT and CPT: Proceedings of the NCEER Workshop on Evaluation of Liquefaction Resistance of Soils, T.L. Youd and I.M. Idriss, eds., Technical Report NCEER-97-0022, State University of New York at Buffalo, p. 41-87.

Saucier, R.T., 1977, Effects of the New Madrid earthquake series in the Mississippi alluvial valley: U.S. Army Corps of Engineers Waterways Experiment Station, Miscellaneous Paper S-77-5, 10 p. 
Schmertmann, J.H., 1987, Discussion of "Time-dependent strength in freshly deposited or densified sand," by J.K. Mitchell and Z.V. Solymar, Journal of the Geotechnical Engineering Division, American Society of Civil Engineers, v. 113, no. 2, p. 173-175.

Schmertmann, J.H., 1991, The mechanical aging of soils: Journal of Geotechnical Engineering American Society of Civil Engineers, v. 117, no. 8, p. 1288-1330.

Schnabel, P.B., Lysmer, J., and Seed, H.B., 1972, SHAKE, A computer program for earthquake response analysis of horizontally layered sites: EERC Report 72-12, University of California, Berkeley.

Schneider, J., 1999, Liquefaction response of soils in mid-America evaluated by seismic cone tests: M.S. Thesis, School of Civil and Environmental Engineering Georgia Institute of Technology, Atlanta.

Seed, H.B., 1979, Soil liquefaction and cyclic mobility for level ground during earthquakes: Journal of Geotechnical Engineering American Society of Civil Engineers, v. 105, p. 201-255.

Seed, H.B., and Idriss, I.M., 1971, A simplified procedure for evaluating soil liquefaction potential: Journal of Soil Mechanics and Foundation Engineering American Society of Civil Engineers, v. 97, p. 1249-1274.

Seed, H.B., Idriss, I.M., and Arango, I., 1983, Evaluation of liquefaction potential using field performance data: Journal of Geotechnical Engineering American Society of Civil Engineers, v. 109 , p. $458-482$.

Seed, H.B., Tokimatsu, K., Harder, L.F., and Chung. R.L., 1985, Influence of SPT procedures in soil liquefaction resistance evaluations: Journal of Geotechnical Engineering American Society of Civil Engineers, v. 111, p. 1425-1445.

Sims, J.D., 1975, Determining earthquake recurrence intervals from deformational structures in young lacustrine sediments: Tectonophysics, v. 29, p. 141-152.

Simcock, K.J., Davis, R.O., Berrill, J.B., and Mullenger, G., 1983, Cyclic triaxial tests with continuous measurement of dissipated energy: Geotechnical Testing Journal, American Society for Testing and Materials v. 6, p. 35-39.

Stark, T.D., and Olson, S.M., 1995, Liquefaction resistance using CPT and field case histories: Journal of Geotechnical Engineering American Society of Civil Engineers, v. 121, p. 856-869.

Terzaghi, K., and Peck, R.B., 1967, Soil Mechanics in Engineering Practice, (2nd ed.): John Wiley, New York, 729 pp.

Terzaghi, K., Peck, R.B., and Mesri, G., 1996, Soil Mechanics in Engineering Practice (3rd ed.): John Wiley \& Sons, Inc, Wiley Interscience Publication, p. 193-208. 
Tinsley, J.C., Youd, T.L., Perkins, D.M., and Chen, A.T.F., 1985, Evaluating liquefaction potential, in Ziony, J.I., ed., Evaluating earthquake hazards in the Los Angeles region - An earth sciences perspective: U.S. Geological Survey Professional Paper 1360, p. 263-316.

Tokimatsu, K., 1988, Penetration tests for dynamic problems: Proceedings, $1^{\text {st }}$ International Symposium on Penetration Testing, Orlando, Florida, A.A. Balkema, Rotterdam, v. 1, p. 117 136

Trifunac, M.D., 1995, Empirical criteria for liquefaction in sands via standard penetration tests and seismic wave energy: Soil Dynamics and Earthquake Engineering Elsevier Science, v. 14, p. $419-426$.

Trifunac, M.D., 1999, Discussion of “Assessment of liquefaction potential during earthquakes by Arias Intensity": Journal of Geotechnical and Geoenvironmental Engineering American Society of Civil Engineers, v. 125, no. 7, p. 627.

Tsuchida, H., 1970, Prediction and countermeans against the liquefaction in sand deposits: Seminar in the Port and Harbor Institute, Yokohama, Japan, p. 3.1-3.33 (abstract).

Tuttle, M.P., Cowie, P., and Wolf, L., 1992, Liquefaction induced by modern earthquakes as a key to paleoseismicity: A case study of the 1988 Saguenay event: U.S. Nuclear Regulatory Commission Report NUREG/CP-0119, v. 3, p. 437-462.

Tuttle, M., and Barstow, N., 1996, Liquefaction-related ground failure - A case study in the New Madrid seismic zone, central United States: Bulletin of the Seismological Society of America, v. 86, p. 636-645.

Tuttle, M.P., 1999, Late Holocene earthquakes and their implications for earthquake potential of the New Madrid seismic zone, central United States: Ph.D. Thesis, Department of Geology, University of Maryland, College Park, $250 \mathrm{p}$.

Wood, H.O., and Neumann, F., 1931, Modified Mercalli intensity scale of 1931: Bulletin of the Seismological Society of America, v. 21, p. 277-283.

Yamamuro, J.A., and Lade, P.V., 1998, Steady-state concepts and static liquefaction of silty sands: Journal of Geotechnical and Geoenvironmental Engineering American Society of Civil Engineers, v. 124, p. 868-877.

Yegian, M.K., Ghagraman, V.G., and Harutinunyan, R.N., 1994, Liquefaction and embankment failure case histories: Journal of Geotechnical Engineering American Society of Civil Engineers, v. 120 , no. 3 , p. 581-596.

Youd, T.L., 1973, Liquefaction, flow, and associated ground failure: U.S. Geological Survey Circular 688, $12 \mathrm{p}$. 
Youd, T.L., 1984, Geologic effects - Liquefaction and associated ground failure: U.S. Geological Survey Open-File Report 84-760, p. 210-232.

Youd, T.L., 1991, Mapping of earthquake-induced liquefaction for seismic zonation: Proceedings, Fourth International Conference on Seismic Zonation, Stanford University, Earthquake Engineering Research Institute, v. 1, State-of-the-art papers, p.111-147.

Youd, T.L., and Garris, C.T., 1995, Liquefaction-induced ground-surface disruption: Journal of Geotechnical Engineering American Society of Civil Engineers, v. 121, p. 805-809.

Youd, T.L., Holzer, T.L, and Bennett, M.J., 1989, Liquefaction lessons learned from Imperial Valley, California: Twelfth International Conference on Soil Mechanics and Foundation Engineering Proceedings of Discussion Session on Influence of Local Conditions on Seismic Response, Rio de Janeiro, p. 47-54.

Youd, T.L., and Idriss, I.M., eds., 1997, Proceedings of the NCEER Workshop on Evaluation of Liquefaction Resistance of Soils: Technical Report NCEER-97-0022, State University of New York at Buffalo, $276 \mathrm{p}$.

Youd, T.L., and Noble, K., 1997, Liquefaction criteria based on statistical and probabilistic analyses: Proceedings of the NCEER Workshop on Evaluation of Liquefaction Resistance of Soils, T.L. Youd and I.M. Idriss, eds., Technical Report NCEER-97-0022, State University of New York at Buffalo, p. 210-216.

Youd, T.L., and Perkins, D.M., 1978, Mapping liquefaction-induced ground failure potential: Journal of Geotechnical Engineering Division, American Society of Civil Engineers, v. 104, p. $433-446$.

\section{APPENDIX: DEFINITIONS OF TERMS}

directionality Directionality is the transmission of seismic energy, as manifest in parameters such as maximum acceleration, in a preferred orientation in plan view. The influence of directionality depends on the orientation and type of fault. For example, strike-slip faults tend to transmit more energy along the axis of the fault; normal faults tend to transmit more to the downthrown block; and reverse faults tend to transmit more to the upthrown block.

meizoseismal zone The AGI Glossary of Geology defines "meizoseismal" as "pertaining to the maximum destructive force of an earthquake," from which one could infer that "meizoseismal zone" means the area within, or approximately within, the highest isoseismal (as for example, the area within the highest Modified Mercalli Intensity). Others, however, use the term to refer to the region of higher intensities of the earthquake (note, not highest intensities). We use the term in this later sense. 